\title{
DIGITALCOMMONS
}

@WAYNESTATE-

Wayne State University

$1-1-2017$

\section{Biased and Broken Bodies of Proof: White Heteropatriarchy, the Grand Jury Process, and Performance on Unarmed Black Flesh}

Blanche Bong Cook

Wayne State University

Follow this and additional works at: https://digitalcommons.wayne.edu/lawfrp

Part of the Law and Race Commons

\section{Recommended Citation}

Blanche Bong Cook, Biased and Broken Bodies of Proof: White Heteropatriarchy, the Grand Jury Process, and Performance on Unarmed Black Flesh, 85 UMKC L. Rev. 567, 624 (2017) 


\title{
BIASED AND BROKEN BODIES OF PROOF: WHITE HETEROPATRIARCHY, THE GRAND JURY PROCESS, AND PERFORMANCE ON UNARMED BLACK FLESH
}

\author{
Blanche Bong Cook ${ }^{1}$
}

The intention in torture of humans is ... to silence the other's voice by wrecking his or her body; it is to make the tortured speak the torturer's words instead of his own. ${ }^{2}$

Margaret A. Farley

\section{ABSTRACT}

Although scholars have theorized about systemic racialized police violence, less attention has been given to systemic practices in the investigations and grand jury proceedings surrounding cases of excessive police force and black bodies. ${ }^{3}$ This article, focusing on the shooting death of Michael Brown, emphasizes that it was not just the killing itself, but also the investigation and grand jury proceeding, which exemplify white heteropatriarchal performance on vulnerable bodies. $^{4}$

\footnotetext{
${ }^{1}$ Assistant Professor of Law, Wayne State University School of Law. B.A. Vassar College. J.D. University of Michigan School of Law. Assistant United States Attorney, 2005-2014, United States, Department of Justice. I presented an earlier version of this article as the Keynote Speaker for Vanderbilt Law School Black History Month in February 2015. I would like to thank Angela Harris, Darryl Stewart, Dawn Marcelle, Kristen Barnes, Jonathan Weinberg, Vinay Harpalani, Taja-Nia Y. Henderson, Stacey Floyd Thomas, Juan Floyd Thomas, Steven Shaviro, Justin Long, Robert Sedler, Erica Beecher-Monas, and Chris Lund for their helpful comments on previous drafts. I must extend my sincere gratitude to Tiye Greene, Sharae Smiley, and Phaedra Wainaina, my tireless, loyal, hardworking, and perspicacious research assistants. Any errors are mine.

${ }^{2}$ Margaret A. Farley, Just Love: A Framework for Christian Sexual Ethics 123 (Continuum International Publishing Group 2010).

${ }^{3}$ Throughout this piece, I reference the "black body" in order to underscore the corporeal fleshiness of human life.

${ }^{4}$ In describing Michael Brown's death as a white heteropatriarchal performance on vulnerable bodies, I reference several theorists, most immediately, Anthony Farley's Black Body as Fetish Object, particularly Professor Farley's argument that black bodies have provided canvasses, stages, and theater for the formulation and formation of "whiteness." Anthony Paul Farley, The Black Body as Fetish Object, 76 OR. L. REV. 457, 464 (1997). Farley argues, "The white identity is created and maintained by decorating black bodies with disdain, over and over again." Id. at 463 . "Race is a form of pleasure in one's body which is achieved through humiliation of the Other and then, as the last step, through a denial of the entire process." Id. at 464. "The discourse of race involves lavishly decorating the black body with statistics, stories, and images of violence, narcotics,..." and other racial tags, labels, and branding. Id . at 475 . Whiteness, as an identity, emerges out of this discourse; for "[i]f the black body is the site and cite of all ills, then the white body is not." Id. Moreover, once the black body is branded as the site for all ills, it provides carte blanche for policing, surveillance, and the use of excessive police force because the body and, by extension the "bad" neighborhood, become an indispensable justification for reasonable suspicion as well as probable cause, both of which justify intrusion. See id. As developed throughout this piece, this article argues that the investigation and grand jury proceeding in the case involving Michael Brown and Darren Wilson served these functions.
} 
Discourses and ideologies of white heteropatriarchy, manifest as implicit bias and structural prejudice, frame the way we see evidence, such that the black body itself becomes proof of criminality and the white body itself reflects innocence, goodness, and righteousness. Gendered frameworks of blackness and whiteness not only frame the way we see evidence, they exist before we see the proof; determine what counts as evidence; determine the presumption of innocence, as well as guilt; dictate the outcomes of both the investigation and adjudication; invert the adjudicative process; and reallocate both the order of proof and the burdens of persuasion in grand jury proceedings as well as trials. When police officers kill and brutalize unarmed black people, the grand jury proceeding is inverted, such that prosecutors defend the perpetrators of violence and make the case for justifiable homicide beyond a reasonable doubt, when they would normally aggressively prosecute the targets establishing guilt by a probable cause standard. The unprecedented rates of incarceration making the United States the most carceral nation in history speak to the unbridled success rate of prosecutorial zeal when there is a will and a desire to prosecute. In the case of Michael Brown's killing, however, the failure to obtain an indictment against police officer Darren Wilson accomplished the same task as the killing of Brown itself, which was the vilification of Brown, the valorization of Wilson, and the reassurance of white heteropatriarchal preeminence, vindication, safety, and security. This is particularly imperative to apprehend when considering potential solutions to the problem of racialized and gendered operations of law enforcement: grand jury and court rooms have so far functioned to sanitize, subsidize, and perpetuate the violence of law enforcement, rather than acting as a corrective to it, even as victims of police wrong-doing are encouraged to seek relief from the courts. Thus, in addition to reforms aimed at police officers and methods, substantive changes in both the investigations and prosecutions of cases involving law enforcement violence are imperative, with particular attention to the grand jury proceedings.

\section{INTRODUCTION \& TERMINOLOGY}

With $90 \%$ or higher success rates, ${ }^{5}$ grand jury proceedings epitomize prosecutorial discretion, domain, and power. Yet, in the case of Darren Wilson and numerous other police officers charged with similar acts of violence prosecutors problematically failed to obtain indictments (let alone convictions) for

\footnotetext{
${ }^{5}$ See Ben Casselman, It's Incredibly Rare For A Grand Jury To Do What Ferguson's Just Did, FIVETHIRTYEIGHT (Nov. 24, 2014, 9:30 PM), http://fivethirtyeight.com/datalab/ferguson-michaelbrown-indictment-darren-wilson/; see also Philip Bump, The Rarity of a Federal Grand Jury Not Indicting, Visualized, WASH. POST (Nov. 24, 2014), http://www.washingtonpost.com/blogs/thefix/wp/2014/11/24/the-rarity-of-a-federal-grand-jury-not-indictingvisualized/http://www. washingtonpost.com/blogs/the-fix/wp/2014/11/24/the-rarity-of-a-federal-grand-jury-not-indictingvisualized/.
} 
the deaths of unarmed black citizens. ${ }^{6}$ In questioning the absence of a true bill in the Wilson grand jury proceeding, many critics, commentators, and legal pundits suggest that the answer is obvious; however, when asked exactly what is obvious, responses oscillate. Those on the left of the political spectrum, may ask, "Wasn't it racism?" However, when hard pressed to carefully delineate what is meant by "racism," few can explain in detail. For example, few are willing to say that the mere sight of a black body arouses feelings of suspicion and dangerousness and stimulates a need to control. As another example, few, if any, have suggested an intersectional analysis, specifically that if these were black officers killing unarmed white females, the investigations, grand jury presentations, grand jury results, possible settlements, framing of the evidence, discourses surrounding the proof, trials, and/or proposed solutions would be radically different. Those on the right of the political spectrum, may ask, "Wasn't Brown a thug that deserved it?" "Wasn't Brown wild and dangerous?" Although the answers may seem obvious, it is worth unpacking how the institutional power of courts have masked, obfuscated, and legitimized the operations of white supremacy and heteropatriarchy in these unarmed killings. ${ }^{7}$ Prosecutors and judges have acted in ways that perpetuate the violence of law enforcement, when their proper role should be corrective. Law enforcement has exaggerated the limits of its authority, and both courts and prosecutors have failed to exercise their power to curb arbitrary violence by the

\footnotetext{
${ }^{6}$ The naming of persons of color, including Blacks and Latinas/os, remains highly contested ground, with marginalized groups demanding the authority to self-define, self-proclaim, and self-announce. Thus, it is imperative for me to make several comments at the outset concerning the utility of the words 'black," "Black," and African-American. When used as an adjective, I use "black" and similarly "white." I use 'African-American' and 'Black' interchangeably. When using 'Black,' I capitalize it to reflect the view that Blacks, like Asian Americans, Latina/os, and other 'underrepresented groups,' constitute specific ethnic and cultural groups. Consequently, this requires the designation of a proper noun. See Kimberle' Williams Crenshaw, Race, Reform, and Retrenchment: Transformation and Legitimation in Antidiscrimination Law, 101 HARV. L. ReV. 1331, 1349 (1988); Catherine MacKinnon, Feminism, Marxism, Method, and the State: An Agenda for Theory, 7 Signs: J. OF WOMEN IN CULTURE \& SOC'Y 515, 516 (1982) (noting that 'Black' is more than skin color or pigmentation, but as a cultural heritage, a shared experience, a personal and communal identity, the meaning of which has been deemed synonymous with social stigma).

${ }^{7}$ The recent spate of police shootings of unarmed person dwells at the intersections of race as well as class and gender; however, the thrust of the analysis in the instant piece focuses on race, more specifically white supremacy, racism, and implicit bias. My scholarship on police violence will continue to contextualize the killings of vulnerable persons in the larger theoretical framework of white heteropatriarchy. The use of the term "heteropatriarchy" in this article, therefore, is a placemarker intended for purposes of continuity with my later work. There are clear gender components to the recent spate of killings, and racialized understandings of masculinity directly impact those functions, but I leave to another day an analysis of these shootings with a more nuanced emphasis on the functions of heteropatriarchy.
} 
state, even as victims of police wrong-doing are encouraged to seek redress through the courts. ${ }^{8}$

The recent spate of unarmed shootings of Blacks, typified in the case of Michael Brown and Officer Darren Wilson, functions as sites of white and patriarchal violence on black flesh, ${ }^{9}$ more specifically, implicit bias concretized as structural prejudice during the investigation of Officer Wilson. As a former federal prosecutor with a $100 \%$ success rate in obtaining grand jury indictments in over 100 federal cases, the reasons for the absence of a true bill in the Wilson case are hardly obvious to me or the standard viewer of the American scene. ${ }^{10}$ At least part of the answer, however, to the absence of a true bill in Wilson's case lies in the power of white heteropatriarchal ideologies to invert order and to obfuscate, hide, and legitimize the inversion. These ideologies are manifested with the power and moral authority to turn an indictment proceeding into a vindication process where the alleged perpetrators become the victims and the victims, particularly when they are societally vulnerable, become the villains. Instead of vetting whether Wilson used excessive force, the proceedings vilified Brown and sanitized Wilson, inoculating him from charges of criminality and treachery. ${ }^{11}$ During Wilson's grand jury proceedings, the prosecution put on Wilson's case-in-chief, normally reserved for the defense attorney at trial; this is just one example of several that demonstrate the inverted process in which prosecutors become defense attorneys, grand juries become petit juries, defendants become victims, and victims become villains. Much like rape cases, battered women's cases, sex trafficking cases, and

${ }^{8}$ See, e.g., Supreme Court Sides With Police; Officers Using Deadly Force In Chases Granted More Immunity, LEO AFFAIRS (Nov. 9, 2015), http://www.leoaffairs.com/featured/supreme-court-sideswith-police-officers-using-deadly-force-in-chases-granted-more-immunity/ (explaining the Supreme Court's acquiescence to police perspectives on violence); Doug Wyllie, How 'Comply and Complain' Can Prevent a Future Ferguson, PoliceOne.com (Aug. 7, 2015), https://www.policeone.com/police-trainers/articles/8698431-How-comply-and-complain-canprevent-a-future-Ferguson/ (instructing victims of police misconduct to "comply and complain"). ${ }^{9}$ See supra note 2 and accompanying text.

10 "A Huffington Post-YouGov poll of 1,000 adults released [in 2014] found that 62 percent of African-Americans believed Officer Wilson was at fault in the shooting of Mr. Brown, while only 22 percent of whites took that position." Michael Wines, Reaction to Ferguson Decision Shows Racial Divide Remains Over Views of Justice, N.Y. TIMES (Nov. 26, 2014), http://www.nytimes.com/2014/11/26/us/after-ferguson-announcement-a-racial-divide-remainsover-views-of-justice.html. Analogously, "[i]n 1992, a Washington Post poll found that 92 percent of Blacks - and 64 percent of Whites - disagreed with the acquittal of the Los Angeles police officers involved in the videotaped beating of a black man, Rodney King." Id.

11 After conducting an investigation, the Department of Justice found that "Wilson's actions [did] not constitute prosecutable violations under the applicable federal criminal civil rights statute...." Memorandum from the Dep't. of Justice on The Criminal Investigation Into The Shooting Death of Michael Brown By Ferguson, Missouri Police Officer Darren Wilson (Mar. 4, 2015), available at https://www.justice.gov/sites/default/files/opa/pressreleases/attachments/2015/03/04/doj_report_on _shooting_of_michael_brown_1.pdf. Although the DOJ made a non-prosecutable finding, its report did not analyze the procedural irregularities of the Darren Wilson investigation and grand jury proceeding, which are the subject matters of this article. See id. 
other cases involving societally vulnerable victims, the grand jury proceedings confirmed Wilson's innocence and Brown's villainy. Perhaps too, the absence of a true bill reassured the public that the tools necessary to promote, privilege, and protect white innocence and to annihilate black demonry were alive, well, and resting comfortably within the legal process. ${ }^{12}$

The Wilson proceedings paradigmatically exemplify the manner in which law is intersectionally raced, classed, and gendered, such that black bodies are relegated to places of vulnerability and saturated with the conditions necessary for exploitation, domination, and control. Yet the power of law to reify existing social arrangements and racial hierarchies comes from, among other things, the procedural performance of fairness and neutrality, such that violence and inequality appear natural, necessary, inevitable, and beyond reproach. ${ }^{13}$ The "no true bill" vindicated the right of a white officer to shoot and kill a perceived black threat.

In order to explore the obfuscating, inverting, reassuring properties of the Wilson no true bill, this article proceeds in eight parts. Part II explains and defines key terms used throughout the article, including white supremacy and heteropatriarchy, white heteropatriarchy, implicit bias, and performance. Part III provides background and contextual information about the facts and circumstances surrounding Officer Darren Wilson's shooting Michael Brown. Part IV provides background and contextual information about grand jury proceedings generally. Part V explores the structural biases and inherent conflict of interests that favor white police officers accused of killing black people. Part VI uses a set of multidisciplinary analytical tools to expose the operations of white heteropatriarchy in the Wilson grand jury proceedings. Part V problematizes the underlying societal notions that frame the way we see evidence, particularly implicit bias. Finally, in Part VIII, I argue that a remedy requires measures as comprehensive and ubiquitous as white heteropatriarchy itself, but more specifically solutions aimed at the inner workings and dynamics of law enforcement. I explore efforts, both theoretical and practical, to disrupt the conflation of white heteropatriarchy with law and order, particularly the use of implicit bias research to screen law enforcement candidates in the application process itself.

\footnotetext{
${ }^{12}$ See, e.g., Sunil Dutta, I'm a cop. If You Don't Want To Get Hurt, Don't Challenge Me., Wash. Post (Aug. 19, 2014), https://www.washingtonpost.com/posteverything/wp/2014/08/19/im-a-copif-you-dont-want-to-get-hurt-dont-challenge-me/?utm_term=.e5f629cb3345; Matthew Vadum, Michael Brown: A Criminal and a Thug, FronTPAGE MAG (Aug. 17, 2014), available at $\mathrm{http} / / / \mathrm{www}$.frontpagemag.com/fpm/238860/michael-brown-criminal-and-thug-matthew-vadum.

Both of these articles might suggest a victim-blaming approach that reframes the issues in the Michael Brown/Darren Wilson case as law enforcement needing to use violence to contain [black] criminality.

${ }^{13}$ Crenshaw, supra note 6.
} 


\section{TERMINOLOGY}

Before turning to the main body of the essay, it may be helpful to clarify how and why I use the terms "heteropatriarchy," "white supremacy," and, in combination, "white heteropatriarchy," as well as to define the terms "implicit bias" and "performance," which are key to my analysis of the investigation and grand jury proceedings in the Daren Wilson case.

Heteropatriarchy. Heteropatriarchy is generally defined as a system of power and control based on compulsory heterosexuality, patriarchy, and imposed gender-binary systems. In defining the salient characteristics of heteropatriarchy, Angela Harris emphasizes five "linked assumptions":

First is the assumption that every person is born, and thereafter remains for life, either male or female. Second, one's sex at birth is assumed to determine one's gender; biology therefore controls one's social behavior .... Third, sex/gender causes males and females to be distinctively and dramatically different along dimensions of appearance, character, behavior, interests, and innate abilities.... Fourth, because "opposites attract" and sex differences are complementary, sexual and romantic relationships should occur only between men and women, not between people of the same assigned sex . . . . These four linked assumptions constitute the "hetero" of heteropatriarchy. The fifth assumption provides the "patriarchy": though male and female are opposite sexes, they are not quite equal. Masculinity is the privileged sex/gender. In nearly every setting, as feminists have pointed out, masculine characteristics and attributes are considered superior to feminine ones. ${ }^{14}$

In the case of Michael Brown and Darren Wilson, it must be pointed out that both individuals are socially classified as men, and thus constructed to possess particular traits of masculine character and behavior. As argued infra, expectations surrounding masculinity and violence played a significant role in the inversion of Brown's and Wilson's roles as victim and perpetrator respectively.

White Supremacy. The role of gender norms cannot be fully understood, however, without also considering race. White supremacy refers to a formal system of racial domination based on the belief that Blacks are inferior and should be subordinated and made pliable to white desire. White supremacy is a perennial and omnipresent historical operative that creates a material reality of vulnerability and degradation for black bodies. This grounding stands in sharp contrast to any claims of post-racialism. Post racialism represents a fatigue with race and racial

${ }^{14}$ Angela P. Harris, Heteropatriarchy Kills: Challenging Gender Violence in A Prison Nation, 37 WASH. U. J.L. \& POL'Y 13, 21-22 (2011). 
consciousness. Ignoring race allows for the perpetuation of racialized inequality, rendering the starting point for change invisible. By grounding my analysis in the narrative and legacy of white supremacy and the material reality it creates, this article answers Professor Kimberle' Crenshaw's call "to maintain a contextualized, specified world view that reflects the experience of Blacks." 15 In the case of Michael Brown and Officer Wilson, racial ideologies cleave gender norms, such that white men take on the ideal traits of masculinity (honor, protection, courage, etc.), while black men are imbued with the stark opposite qualities, perceived as crooked, dangerous, aggressive, and in need of being controlled. As other scholars have noted, black men are hypermasculinized and hypersexualized, and this has historically contributed to their vulnerability to white violence. ${ }^{16}$

White Heteropatriarchy. "[H]ierarchies of race, class, sexual orientation, and gender..." all coalesce to delineate groups of women, as well as men, "as vulnerable to the violence of other men."17 Although Brown's death and the legitimization of his killing through the criminal justice system is made explicable as a function of racial violence, the codes of gender, class, and sexuality also explain the dynamics leading to his death as well as the grand jury's promotion, protection, and vindication of white hetero-patriarchal order. When highlighting the dynamics of power as it is raced, classed, and gendered, white heteropatriarchy refers to a racialized system of power and control based on compulsory heterosexuality, patriarchy, and an imposed gender-binary system.

Implicit Bias. Cynthia Lee defines implicit bias as "unintentional bias arising from 'attitudes or stereotypes that affect our understanding, decisionmaking, and behavior, without our even realizing it." 18 Implicit bias is the meaning we attach to objects and bodies in the unfiltered and unregulated mind. Implicit bias is the nanosecond associations of the black body with suspicion, dangerousness, and the need to be controlled and the equally immediate pairing of whiteness with innocence, righteousness, privilege, and the need to be vindicated. Through the lens of implicit bias, blackness is the evidence of evil and whiteness is the evidence of innocence. Implicit bias research demonstrates that pathology perpetually clings to the black body and innocence melds with the white body; thus, even where the white body is engaged in treachery, it is perceived as innocent and where the black body is engaged in innocence, it is perennially pathological. Even when a white police officer murders an unarmed black youth in broad daylight on a summer day in the middle of a well-traversed public street, implicit

${ }^{15}$ Crenshaw, supra note 6 (citing Matsuda, Looking to the Bottom: Critical Legal Studies and Reparations, 22 HARV. L. REV. 323 (1987)).

${ }^{16}$ See generally Harris, supra note 14; see also ANGELA Y. DAvis, WOMEN, RACE, AND CLASS $172-$ 201 (Random House, 1981).

${ }^{17}$ Angela P. Harris, Gender, Violence, Race, and Criminal Justice, 52 StaN. L. Rev. 777, 779 (2000).

${ }^{18}$ Cynthia Lee, Making Race Salient: Trayvon Martin and Implicit Bias in A Not Yet Post-Racial Society, 91 N.C. L. REv. 1555, 1559 n.23 (2013) (citing Jerry Kang et al., Implicit Bias in the Courtroom, 59 UCLA L. REv. 1124, 1126 (2012)). 
bias, which saturates both public and legal discourses, frames the white shooter as valiant and the black victim as demonic. Some discussions of implicit bias couch the term in innocent language and understandings, suggesting that it reflects mere ideas, not action; is lodged in the subconscious, where it cannot be controlled; is shared with black people (they have implicit bias too); and is reinforced by outside influence, as opposed to being conscious and willful. In contrast, I argue that implicit imperatives ${ }^{19}$ inform material reality, not the least of which those where people get shot. ${ }^{20}$ Implicit bias does refer to subconscious ideas, but these ideas also manifest as actions with consequences; moreover, social and structural inequality makes the implicit bias of some groups (such as police officers) more materially dangerous than that of others. Rather than focusing on the unconscious or non-volitional aspects of implicit bias, I focus on the concretization of implicit bias in legal structures - something we can and do have more control over. Investigations of officer-involved shootings, and in particular the grand jury procedure, should function to challenge and undo the effects of implicit bias, rather than enshrining such bias in law. ${ }^{21}$

${ }^{19}$ Stacey M. Floyd-Thomas \& Juan M. Floyd-Thomas, The Altars Where We Worship: The Religious Significance of Popular Culture (2016).

${ }^{20} \mathrm{Far}$ from an idea with no consequence in material reality, the omnipresence and entrenchment of white heteropatriarchy systemically persists in the United States. The poverty rate for non-Hispanic Whites was $9.6 \%$ in 2013 and $27.2 \%$ for Blacks in 2013. DeNavas-Walt, Carmen \& Bernadette D. Proctor, Income and Poverty in the United States: 2014, U.S. CENSUS BuREAU, Current Population Reports, P60-252, at 12-13 (U.S. Government Printing Office, Washington, DC, Sept. 2015). "[M]edian per capita family income for [Blacks and Hispanics] is below $60 \%$ of levels for nonHispanic Whites . . ." Carlos Gradin, Poverty Among Minorities in the United States: Explaining the Racial Poverty Gap for Blacks and Latinos, 44 Applied Econ. 3793, 3793 (2012). In 2006, Black unemployment rate was $57 \%$ and White unemployment rate was $62 \%$. Id. at 3796 . In $2006,18 \%$ of Blacks went to college and $33 \%$ of Whites went to college. Id. "Broken down by race, approximately thirty-three percent of African-American children and thirty percent of Latina/o children live in poverty compared to only nine percent of white children." Andrea Charlow, Race, Poverty, and Neglect, 28 WM. MitChELL L. ReV. 763, 767-68 (2001). "31 percent of white children - 11.7 million - live in low-income families; 65 percent of black children - 6.4 million - live in low-income families." Yang Jiang, Mercedes Ekono, \& Curtis Skinner, Basic Facts About Low-Income Children: Children Under 18 Years, 2013, NAT'L CTR. FOR CHILD. IN POVERTY (2015).

${ }^{21}$ It should be noted that there are essentially two threads of argument with respect to the rhetoric surrounding implicit bias: (1) it is a subconscious association upon which we have no control or (2) it takes its power from cultural reinforcement and can be mitigated or reversed with conscious effort, which of necessity, requires awareness. If the first is true, then persons with implicit bias cannot have authority over persons against whom they have implicit bias. This would include education, sentencing, and medical treatment, just to name a few areas. Such conclusion is unacceptable. Instead, making race salient and conscious efforts to reverse the impact of implicit bias training produces more equitable results. See, e.g., Robert J. Smith, Reducing Racially Disparate Police Outcomes: Is Implicit Bias Training the Answer?, 37 U. HAw. L. REV. 295, 300-02 (2015). In some sense implicit bias is a narrative to describe and capture the operations of racism, white supremacy, and white heteropatriarchy. Implicit bias manifests on a spectrum of microaggressive to macroaggressive behavior in which the actor is neither unconscious nor laboring under a seizure. The implicit bias conduct has volition. If it is true, that implicit bias cannot be controlled, then it follows, that individuals who have implicit bias cannot have power and authority over persons against 
Performance. Finally, I refer to the incidents under discussion, beginning with the shooting of Brown and stretching to include the investigation, prosecution, and failure to indict Office Wilson, as a "performance" of white heteropatriarchy. What does this mean, and how is it helpful for understanding the issues at hand? The notion of "performance" is crucial to feminist and queer theorizations of gender, and of gendered power. Specifically, theorists have suggested that gender, rather than being an essential trait of sexed bodies, is instead made "real" through repetitive social performance. ${ }^{22}$ Just as the notion of performance is crucial to understanding lived categories of race and gender, so too is it necessary to understanding law, which - beyond being a collection of codified rules - draws its power (and legitimacy) from procedural performance. ${ }^{23}$ Indeed, the social import of law comes in large part from its practice rather than from its mere codification. ${ }^{24}$ "Performance," therefore, describes a set of interrelated and simultaneous processes: the gendered and racialized performances of masculinity that are crucial to understanding Wilson's encounter with Brown; the performance of law and procedure during the investigation and grand jury proceeding; and the ways in which both sets of performances functioned to reiterate and reify social inequality as material expression of life and death.

\section{FACTS OF THE CASE}

On August 9, 2014, in broad daylight on a well-traveled public street, Darren Wilson, a white police officer, shot and killed Michael Brown, an unarmed black teen, in Ferguson, Missouri, a suburb of St. Louis. Wilson shot at Brown 12 times, ${ }^{25}$ emptying his service revolver with the exception of one bullet. From the outset of the grand jury proceedings, the prosecution laid the foundation for Wilson's defense. Before the prosecution allowed Wilson to testify and provide his story to the grand jurors, the prosecution showed the grand jurors a video of Brown robbing a local convenient store while one of the prosecutors described Brown as "brash," "threatening," and "intimidating." ${ }^{26}$ By contrast, before Wilson

whom they have implicit bias. This may not be acceptable, workable, or practicable. Instead, research has demonstrated that implicit bias and di-bias training can ameliorate the impact of implicit bias. See id. It should also be noted that implicit bias may inform the way in which implicit bias is discussed, identified, and framed. See id.

22 See Judith Butler, Gender Trouble 6-7 (Linda J. Nicholson, ed., Routelage 1990).

${ }^{23}$ See, e.g., J.M. Balkin and Sanford Levinson, Law As Performance, in 2 LAw and Literature: Current Legal Issues 729 (Michael Freeman \& Andrew D. E. Lewis, eds., Oxford Univ. Press, 1999); KENII YosHINO, CoverING (Random House, 2006), available at http://kenjiyoshino.com/KY/covering/.

${ }^{24}$ Balkin and Levinson, supra note 22.

${ }^{25}$ Rachel Clarke \& Mariano Castillo, Michael Brown shooting: What Darren Wilson Told the Ferguson Grand Jury, CNN, (Nov. 26, 2014, 11:32 AM), http://www.cnn.com/2014/11/25/justice/ferguson-grand-jury-documents/.

${ }^{26}$ Transcript of Grand Jury, vol. 4 at 84-86, Ferguson Police Shooting, Sept. 10, 2014, available at https://www.documentcloud.org/documents/1370517-grand-jury-volume-4.html [hereinafter 
testified, the prosecution painted Wilson as easy going, "a good officer," and not one to "go . . . look[ing] for trouble." At the beginning of Wilson's direct examination, the prosecution further solidified Wilson's defense, letting Wilson establish his size - nearly 6 -foot -4 , weighing around 210 pounds $^{27}$ and allowing Wilson to describe Brown as a "demon," 28 "Hulk Hogan," 29 "aggressive," and from a bad neighborhood, known for violence, guns, gangs, and drugs. ${ }^{30}$

After establishing the contrasting frames of "good" Wilson and "evil" Brown, ${ }^{31}$ the prosecution gave the grand jurors an erroneous, outdated, and constitutionally overruled Missouri statute that established a complete defense for Wilson's use of excessive police force against "evil" Brown. ${ }^{32}$ The Supreme Court

Transcript, vol. 4]; see also Katherine Goldwasser, The Prosecution, the Grand Jury, and the Decision Not to Charge, in Ferguson's Fault LInes: The RaCe Quake That Rocked A Nation 37, 44 (Kimberly Jade Norwood ed., ABA Publishing 2016), available at http://www.americanbar.org/content/dam/aba/multimedia/cre/materials/2016/05/cel605fss.authche ckdam.pdf.

27 Transcript of Grand Jury, vol. 5 at 198, State v. Wilson, Sept. 16, 2014, available at https://www.documentcloud.org/documents/1370518-grand-jury-volume-5.html [hereinafter Transcript, vol. 5]. It should also be noted that at the outset of Wilson's direct examination, the prosecutor asked Wilson if he wanted to be in the grand jury to tell the grand jurors what happened, to which he responded in the affirmative. $I d$. at 197-98. The inference here is that Wilson volunteered his testimony, as opposed to providing it via subpoena, yet another framing of Wilson's testimony in a manner most beneficial to Wilson's innocence, as opposed to his adjudication. Goldwasser, supra note 26.

28 Transcript, vol. 5, at 225 .

${ }^{29}$ Transcript, vol. 5, at 212 .

30 Transcript, vol. 5 , at 170 .

${ }^{31}$ Goldwasser, supra note 26.

32 At the outset of the grand jury proceedings, the prosecution read the grand jurors Mo. REV. STAT. $563(3)(2)(a)(1979)$, a statute analogous to that overruled by the Supreme Court in Tennessee $v$. Garner. 471 U.S. 1, 11-12 (1985). In Garner, the Supreme Court struck down a Tennessee statute, which like the Missouri statute, allowed the police to use deadly force on a fleeing felon where the suspect was neither armed nor seemingly dangerous. Id. In Garner, the Court held, "Where the officer has probable cause to believe that the suspect poses a threat of serious physical harm, either to the officer or to others, it is not constitutionally unreasonable to prevent escape by using deadly force. Thus, if the suspect threatens the officer with a weapon or there is probable cause to believe that he has committed a crime involving the infliction or threatened infliction of serious physical harm, deadly force may be used if necessary to prevent escape, and if, where feasible, some warning has been given." Id. Thus, the statute that the prosecution provided the grand jurors during the outset of the grand jury proceeding was not only erroneous, it was much more favorable to Wilson. See also Nicole Flatow, This Mistake Skewed The Law In Darren Wilson's Favor, THINk Progress (Nov. 30 2014), https://thinkprogress.org/this-mistake-skewed-the-law-in-d arren-wilsons-favor9374d3fba17\#.fwlilvor6.https://thinkprogress.org/this-mistake-skewed-the-law-in-darren-wilsonsfavor-9374d3fba17\#.fwlilvor6. It should also be noted that, after Garner, the Supreme Court decided two more cases that govern the terrain of the reasonableness of a police officer's use of excessive force. Scott v. Harris, 550 U.S. 372 (2007); Graham v. Connor, 490 U.S. 386 (1989). In Scott, the Court essentially adopted a totality of the circumstance test finding that what constitutes an unreasonable seizure of a person, is not susceptible to "an easy-to-apply legal test." Scott, 550 U.S. at 383. According to Justice Scalia, "Garner did not establish a magical on/off switch that triggers rigid preconditions whenever an officer's actions constitute 'deadly force."' Id. at 372 . In 
had earlier over-ruled an analogous statute in a case it decided years earlier. The statute the prosecutors provided to the grand jury was not only unconstitutional, but it was more favorable to Wilson than the governing and applicable law. Two months after providing the erroneous statute and having allowed that erroneous statute to frame the grand jurors view of the evidence, the prosecution finally gave the grand jurors the correct law governing deadly use of police force. ${ }^{33}$

Having set the frame of contrasting images and having provided an unconstitutional statement of law more favorable to Wilson, the prosecution called Wilson to testify and allowed him to tell the grand jurors why Brown was dangerous and why he was justifiably compelled to use deadly force against Brown. Wilson stated that in the nanoseconds it took for Brown to walk past his moving vehicle, he noticed stolen cigarillos in Brown's hand. ${ }^{34}$ According to Wilson, after he told Brown not to walk in the middle of the street, Brown, unarmed, struck Wilson repeatedly in the face while Wilson, in uniform and armed, was seated in a readily identifiable police-issued SUV. ${ }^{35}$ Wilson claimed that Brown paused from pummeling him in his SUV long enough to pass the cigarillos to Dorian Johnson, Brown's companion who was present during the shooting and the robbery of the convenient store. ${ }^{36}$ Wilson testified that during his beating from Brown, he contemplated using his taser, mace, and flashlight against Brown. ${ }^{37}$ Wilson stated that when he pointed his firearm directly in Brown's face and told Brown to "stand back or I'm going to shoot you," Brown retorted that Wilson was "too much of a pussy" to shoot. ${ }^{38}$ Wilson claimed that, after he shot at Brown within his SUV, Brown paused, stared at him like a demon, and charged him again. ${ }^{39}$ Wilson also testified that Brown continuously charged him after he had

Scott, the Court found law enforcement actions reasonable where a deputy sheriff rammed a motorists from behind to end a public endangering car chase after the deputy sought to stop the defendant for driving 73 miles-per-hour in a 55-mile zone. Id. at 373-74. The deputy's actions caused the car to crash and left the defendant a quadriplegic. Id. at 375. The Court reasoned that the fleeing driver "posed a substantial and immediate risk of serious physical injury to ..." innocent persons on the road, rendering the officer's action-seizure-reasonable. Id. at 372. In Graham, the Court clarified its pronouncements in both Garner and Scott, stating, "[W] . " is "that all claims that law enforcement officers have used excessive force-deadly or not-in the course of an arrest, investigatory stop, or other 'seizure' of a free citizen should be analyzed under the Fourth Amendment and its 'reasonableness' standard ...." Graham, 490 U.S. at 395.

${ }^{33}$ On September 15, 2014, the prosecution provided the grand jurors with the unconstitutional statute. See Transcript, vol. 5, at 5. On November 21, 2014, the prosecution provided the correct statute. See Transcript of Grand Jury, vol. 24 at 134, Ferguson Police Shooting, Nov. 21, 2014, available at https://www.documentcloud.org/documents/1370537-grand-jury-volume-24.html [hereinafter

Transcript, vol. 24]; see also Flatow, supra note 32.

${ }^{34}$ Transcript, vol. 5, at 209.

${ }^{35}$ Transcript, vol. 5, at 208-10.

${ }^{36}$ Transcript, vol. 5, at 211-12.

${ }^{37}$ Transcript, vol. 5, at 213-14.

${ }^{38}$ Transcript, vol. 5, at 214.

${ }^{39}$ Transcript, vol. 5, at 224-25. 
already fired four separate rounds of bullets, hitting Brown with 6 of those bullets. $^{40}$

After hearing the evidence, the grand jury declined to indict Wilson. In addition, Wilson's supporters raised nearly a half million dollars on Wilson's behalf, allowing him and the wife he married while under Brown's murder ${ }^{41}$ investigation, to move, buy a new home, and pay his legal expenses. ${ }^{42}$

As the investigation and grand jury proceeded, several layers of investigative and prosecutorial irregularities ${ }^{43}$ emerged, each peculiarity reinforcing the problems exacerbated by the other. At the scene of the shooting itself, Wilson was allowed to leave unescorted, before being formally interviewed or processed; to wash blood off his hands; and to place his recently fired weapon into an evidence bag himself, all of which violated protocols for handling a crime scene and securing evidence. ${ }^{44}$ The officers that interviewed Wilson immediately after the shooting did not record the interview..$^{45}$ An investigator from the medical examiner's office made a decision not to take measurements at the crime scene and

${ }^{40}$ See Frances Robles \& Julie Bosman, Autopsy Shows Michael Brown Was Struck at Least 6 Times, N.Y. TIMES, (Aug. 17, 2014), http://www.nytimes.com/2014/08/18/us/michael-brown-autopsyshows-he-was-shot-at-least-6-times.html.

41 The use of the word "murdering" connotes a legal conclusion that ordinarily requires a trial and a jury's finding of guilt. In the case of Michael Brown, there was no indictment, let alone a trial or finding of guilt. As a result, I generally refer to Darren Wilson's "killing" of Brown or Brown's "killing" to reference the events surrounding Brown's death. From time to time, however, I reference the "murder investigation" surrounding Brown's killing because there was an investigation and adjudication surrounding the events, however flawed.

42 Jake Halpern, The Cop, NEW Yorker, (Aug. 10 \& 17, 2015), http://www.newyorker.com/magazine/2015/08/10/the-cop.

${ }^{43}$ Whether the Wilson investigation technically breached any rules or ethical codes in its problematic prosecution of Wilson is debatable, particularly given the broad discretion afforded prosecutors in the grand jury; however, the Wilson grand jury proceedings were rife with numerous procedural irregularities out of step with typical grand jury practice and at complete odds with the grand jury proceedings that have led to America becoming the most carceral nation in history. In addition, the procedural irregularities in the Wilson proceeding sparked the American Civil Liberties Union of Missouri to file a civil action on behalf of a person known only as "grand juror Doe," and a lawsuit filed by the American Civil Liberties Union of Missouri. Ryan J. Reilly, Darren Wilson Grand Juror Sues, Accusing Ferguson Prosecutor Of Mischaracterizing Case, Huffington Post (Jan. 5, 2015) http://www.huffingtonpost.com/2015/01/05/bob-mcculloch-wilson-case_n_6417370.html. In the complaint, Doe states, "From Plaintiff's perspective, the presentation of evidence presented to the grand jury investigating Wilson, differed markedly and in significant ways from how evidence was presented in the hundreds of matters presented to the grand jury earlier in its term." Id. Doe's complaint also stated that the "investigation of Wilson had a stronger focus on the victim Brown than in any other cases" presented to the grand jury. The juror also states in the lawsuit, that "explanation of the law was made in a muddled and untimely manner" compared with the other cases that were presented to the grand jurors.

44 Jerry Markon \& Tom Hamburger, Unorthodox Police Procedures Emerge In Grand Jury Documents, WASH. PoST (Nov. 25, 2014), https://www.washingtonpost.com/politics/seeminglyunorthodox-police-procedures-emerge-in-grand-jury-documents/2014/1 1/25/48152574-74e0-1 le4bdlb-03009bd3e984_story.html.

${ }^{45}$ Id.; Transcript, vol. 5 , at 85 . 
arrived at the scene having decided that the incident between Brown and Wilson was "self-explanatory."46

During the grand jury proceeding, when the prosecutors allowed Wilson to testify, the prosecutors utterly abandoned their cross-examining role, which contrasted sharply with their treatment of their own witnesses whose testimony they scoured. ${ }^{47}$ The prosecutors did not ask Wilson, the paradigm of a selfinterested witness, what he reported to his supervisor on the day of the shooting nor did they attempt to track the consistency, or lack thereof, of Wilson's narrative, which he changed several times. ${ }^{48}$ Within six days of the shooting, Ferguson police released a video of Brown robbing a convenient store. ${ }^{49}$ On the same day, Police Chief Thomas Jackson publically announced that Wilson was not aware that Brown "was a suspect in the case" and instead had stopped him and a companion "because they were walking down the street blocking traffic." ${ }^{\text {" Cho }}$ Chief Thomas was himself the target of several race discrimination complaints and later resigned after the scathing Department of Justice (DOJ) Report castigated the City of Ferguson for systemically targeting Blacks. ${ }^{51}$ Despite Chief Thomas's public proclamation that Wilson did not know that Brown was a suspect in the convenient store robbery, Wilson testified before the grand jury that he passed Brown and Johnson in the street, told them to walk on the sidewalk, drove past them, absorbed an epithet from Brown, backed up his car, and in that instant saw the stolen cigarillos in Brown's hand ${ }^{52}$ At no point, did the prosecutor ask Wilson why the Chief of Police would announce that Wilson did not know about the robbery. ${ }^{53}$ Because the Rules of Evidence do not apply to grand jury proceedings, the question would have been fair game and Wilson free to say that he was not responsible for the Chief's statements, if that were his answer. ${ }^{54}$ The prosecution could have also crossexamined Wilson about anything he might have said that would lead anyone within the department to believe that he had not in fact heard the robbery dispatch, which would have greatly diminished the reasonableness of his use of force on Brown.

\footnotetext{
${ }^{46} \mathrm{Id}$.

${ }^{47}$ See Transcript, vol. 5, at 196-281.

48 See id.

${ }^{49}$ Tanzina Vega, Timothy Williams, \& Erik Eckholm, Dueling Police Statements as Anger Rises in Missouri, N.Y. TIMES (Aug. 16, 2014) at A1, available at http://www.nytimes.com/2014/08/16/us/darren-wilson-identified-as-officer-in-fatal-shooting-inferguson-missouri.html

${ }^{50}$ John Eligon, Ferguson Police Chief, Thomas Jackson, Steps Down Amid Criticism, N.Y. TIMES (March 11, 2015), http://www.nytimes.com/2015/03/12/us/ferguson-police-chief-thomas-jacksonsteps-down-michael-brown.html.

si Id.

52 Transcript, vol. 5, at 208-09.

53 See id. at 196-281.

54 "While the Federal Rules of Evidence are not binding on Missouri courts, they are suggestive." 33 Mo. Prac., Courtroom Handbook On Mo. Evid. § 101.4 (2016 ed.); see also Boyer v. City of Potosi, 77 S.W.3d 62, 69 (Mo. Ct. App. E.D. 2002). The reach of the Federal Rules of Evidence is set out in Rules 101 and 1101; see also Federal Rules of Evidence 1101(d)(2).
} 
Similarly, the prosecution could have cross-examined Wilson about the likelihood of his seeing the cigarillos in Brown's hands in the nanoseconds that it took Wilson to drive past Brown or the dubiousness of his allegedly hearing the robbery dispatch before seeing Brown, which stands in stark contrast to his telling the robbery suspects to refrain from jaywalking. Nevertheless, we will never know Wilson's responses because the prosecution never confronted him. Furthermore, on the day of the shooting, the first person Wilson reported to was his supervising officer. Wilson's supervising officer testified, under oath, to the grand jury that Wilson reported to him after the shooting and in later conversations that he was not aware of the convenient store robbery and that Brown and Johnson's jaywalking drew his attention to them. ${ }^{55}$ Asking Wilson why his supervisor would say that Wilson was unaware of the robbery when he confronted Brown would have been fair game in the grand jury. The question would have allowed the grand jurors to inspect Wilson's demeanor evidence when being challenged about his story; however, such demeanor evidence does not exist and we will never know what Wilson's answer would have been because the prosecution utterly failed to confront Wilson about this glaring evidentiary conflict. Despite these glaring evidentiary conflicts that went to the core of Wilson's initial encounter with Brown, reason for stopping him, and justification for the use of force, the prosecution never once challenged Wilson. ${ }^{56}$

Although the prosecution abandoned its cross-examining function with Wilson and relinquished any possibility of obtaining subsequent impeachment materials, to challenge Wilson in the future, the prosecution engaged an unbridled decimation of its own witnesses and permanently damaged their credibility for any future proceeding, such as the then ongoing federal probe as well as any civil action Brown's family could later bring. ${ }^{57}$ In stark contrast to the rigorous confrontation

${ }^{55}$ Transcript, vol. 5, at 52-53, 57-58, 206-209.

${ }^{56}$ Goldwasser, supra note 25 , at 45.

${ }^{57}$ In decimating its own witnesses, the prosecution created Giglio materials that could later be used to undermine the credibility of its witnesses - a feat highly peculiar in any criminal investigation. Giglio information or material references material tending to impeach the character or testimony of the prosecution witness in a criminal trial. Giglio v. United States, 405 U.S. 150, 153 (1972). Giglio materials may include plea agreements, where the prosecution and witness have brokered a recommended lower sentence to the sentencing court in exchange for more testimony from the witness if the case proceeds to trial. Id. By way of explanation and in order to set the historical development of Giglio, fifty-three years ago in Brady v. Maryland, the Supreme Court held that due process requires the prosecution to provide the defense upon request any evidence favorable to the accused which is material either to guilt or to punishment. 373 U.S. 83, 88 (1963). Over twenty years ago, in Giglio, the Supreme Court held that the government's Brady obligation to provide evidence to the defense encompasses evidence affecting a government witness' credibility. Giglio, 405 U.S. at 154. The prosecution violates due process when it "withholds evidence on demand of an accused which, if made available, would tend to exculpate him or reduce the penalty. Brady, 373 U.S. at 87. However, the prosecution "cannot be compelled to disclose impeachment material which would be covered by the Jencks Act relating to any potential government witness, whether it be a witness in the case-in-chief or a rebuttal witness." United States v. Presser, 844 F.2d 1275, 1285 (6th Cir. 1988). "Further, the government need not disclose impeaching material in its possession relating to any 
of its own witnesses, prosecutors gifted Wilson leading questions, which paved the way for him to solidify his story. ${ }^{58}$ "For example, a prosecutor told Wilson, 'You felt like your life was in jeopardy,' followed by, 'And use of deadly force was justified at that point, in your opinion?[,]"'59 providing Wilson with an opportunity to fortify his claim of a reasonable use of force in response to a perceived threat. By contrast, the prosecutors rigorously cross-examined witnesses who contradicted Wilson's testimony, ${ }^{60}$ elaborating the discrepancies between their prior inconsistent statements and detailing the criminal histories of a witness, particularly Dorian Johnson, Brown's companion and the person that had accompanied Brown to the convenience store robbery, the video of which was released long before any police reports related to the incident between Wilson and Brown. ${ }^{61}$ In fact, prosecutors played the video of Brown robbing the store, when it called Johnson to testify, and interrogated Johnson about the incident.

Although the prosecutors ${ }^{62}$ did not challenge Wilson about his prior inconsistent statements, contradictions in his testimony, or discrepancies between his testimony and other proof, they scoured their own witnesses about inconsistencies in their accounts. In the process of decimating their own witnesses, the prosecution created Giglio materials that Wilson's attorney could later use to cross-examine the witnesses, destroying their credibility, if the case had gone to trial as well as in any possible federal or civil proceeding in which the witness might be called to testify ${ }^{63}$ Unlike their delicate treatment of Wilson, prosecutors fully elaborated the contradictions of their witnesses. As an example the prosecution played a recorded interview with a witness where the witness stated, "Yes, I personally saw him on his knees with his hands in the air." the prosecution cross-examined the witness with the contradictions in his various accounts. In another example, the prosecution stated to its witness, "Basically just about everything that you said on August 13th, and much of what you said today, isn't consistent with the physical evidence that we have in this case, O.K.?"65

In many respects, the prosecution put on a better defense of Wilson in the grand jury proceedings than his defense attorney could have ever offered in Wilson's case in chief at trial. In the grand jury proceeding, the prosecution not

potential defense witness where that impeaching material does not meet the Brady test of being material and exculpatory." Id. In sum, the prosecution is not constitutionally obligated to release exculpatory information about a witness prior to trial.

${ }^{58}$ See Transcript, vol. 5, at 280.

${ }^{59}$ Marjorie Cohn, Prosecutor Manipulates Grand Jury Process to Shield Officer, HufFInGTON Post (Jan. 29, 2015), http://www.huffingtonpost.com/marjorie-cohn/prosecutor-manipulates-grand-juryto-shield-officer_b_6240578.html.

${ }^{60} \mathrm{Id}$.

${ }^{61}$ See generally Transcript, vol. 4, at 13, 31-37, 164, \& 171-76; see also Julie Bosman et al., Amid Conflicting Accounts, Trusting the Officer, N.Y. TimES, Nov. 26, 2014, at A1.

${ }^{62}$ See generally Transcript, vol. 4, at 13, 31-37, 164, \& 171-76.

${ }^{63}$ See id.

${ }^{64} \mathrm{Id}$.

${ }^{65} I d$. 
only allowed Wilson to testify without challenge, but also brought in character evidence to buttress Wilson and to remove the potential sting of any racial critique to explain Wilson's conduct. Had Wilson been indicted and proceeded to trial, the Rules of Evidence would have governed his testimony and he would have been subject to cross examination. As an example of the character witnesses the prosecution proffered to the grand jury, on November 11,2014, the prosecutors presented one of Wilson's former supervisors from another police force, and asked about his relationship with the black community as well as standard police practices governing the use of deadly force. ${ }^{66}$ "The witness had nothing but positive things to say about Officer Wilson." ${ }^{\prime 67}$ This is particularly ironic because the city council that supervised Wilson's previous employer, another police department, dismantled the police force that had employed Wilson due to tensions between white officers and black civilians. ${ }^{68}$ The same city council elected to rebuild the police force with new officers, leaving Wilson unemployed. ${ }^{69}$ The prosecution made no effort to question Wilson about any of that.

Further exacerbating the layers of reinforcing procedural irregularities, the prosecutors failed to recommend specific charges against Wilson to the grand jurors. ${ }^{70}$ Typically when a grand jury serves in its accusatory capacity, as opposed to its investigatory function, at the outset of the proceeding, prosecutors recommend specific charges to the grand jurors by presenting a proposed indictment, reading the proposed indictment to the grand jurors, and advising the grand jurors about what anticipated evidence will satisfy each element of a crime under a probable cause standard. ${ }^{71}$ Prosecutors can also explain the confusing details regarding the elements of any offense; how elements of different offenses are distinguishable from one another, which is particularly useful in describing the different elements of homicide; and how specific evidence may satisfy the confusing elements of an offense both at the outset of the proceedings and again at the end of the proceedings, as a reminder; thereby providing the grand jurors with an initial frame, filter, or context through which the grand jurors can screen the

\section{${ }^{66} \mathrm{Id}$.}

${ }^{67} I d$.

${ }^{68}$ Carol D. Leonnig, Kimberly Kindy \& Joel Achenbach, Darren Wilson's First Job Was On A Troubled Police Force Disbanded By Authorities, WASH. Post (Aug. 23, 2014), https://www.washingtonpost.com/national/darren-wilsons-first-job-was-on-a-troubled-police-forcedisbanded-by-authorities/2014/08/23/1 ac796f0-2a45-1 le4-8593-da634b334390_story.html.

${ }^{69} I d$.

${ }^{70}$ See Goldwasser, supra note 26 , at 38-39.

${ }^{71}$ It is worth underscoring that the prosecution can make a "recommendation" or a "suggestion" as to possible charges against the suspect as well as what evidence satisfies those charges. The prosecution cannot usurp the function of the grand jury, which is to make an independent determination as to whether there is enough evidence to charge the suspect under a probable cause standard. The prosecution can make a recommendation without usurping the ultimate function of the grand jury by reminding the grand jurors that what the prosecution says is not evidence, but is solely intended to provide legal guidance as the grand jurors see the evidence and ultimately make the final determinations in their deliberations. 
evidence and an ending coda reminding the grand jurors of what they have seen and how that evidence satisfies the elements of a crime. In the Wilson proceeding, however, prosecutors made no recommendation about what to charge against Wilson, leaving the grand jurors to decide without guidance. ${ }^{72}$ The prosecution's failure to make a charging recommendation to the grand jury placed the grand jurors in a state more confusing than what a petit jury would experience because had the case proceeded to a trial, the petit jurors would have had the advantage of an adversarial process (if there was a will to prosecute) that would advocate for Brown through the presentation of charges, proof, and jury instructions to guide their deliberations.

As Law Professor Katherine Goldwasser argues, the prosecution's failure to recommend specific charges to the grand jurors in order to frame their viewing of the evidence and ultimate deliberations was particularly problematic for two additional reasons. First, the prosecution unleashed a deluge of evidence on the grand jurors. ${ }^{73}$ Typically, and where there is a will to prosecute, the prosecution presents a case with laser focused and edited evidence reflective of its agenda, which is to obtain an indictment against the target (again, where there is a will to obtain an indictment). In the Wilson proceeding, however, the prosecution unleashed a torrent of evidence unbridled in scope and without guidance. Second, further layering the confusion from subjecting the grand jury to a deluge of evidence without guidance through a charging recommendation, at the outset of the grand jury proceedings, the prosecutors gave the grand jurors a law related to Wilson's defense that was outdated and that the United States Supreme Court had overruled. ${ }^{74}$ Although the prosecutors failed to recommend charges against

\footnotetext{
${ }^{72}$ Bosman supra note 61; see also Goldwasser, supra note 26, at 38-39.

${ }^{73}$ As Goldwasser argues, at the outset, Robert Mcculloch eliminated the sting of the procedural irregularity of unleashing a deluge of evidence on the grand jurors by explaining, "Absolutely everything will be presented to the grand jury, every scrap of paper that we have, every photograph that was taken, every bit of paper that we have, every photograph that was taken, every bit of physical evidence that was been gathered, every video clip, anything that we can get." Goldwasser, supra note 25, at 40 (citing Robert McCulloch, Prosecuting Att'y for St. Louis Cnty., MO, Press Conference, KSDK.COM (Aug 13, 2014)).

${ }^{74}$ At the outset of the grand jury proceedings, the prosecution read the grand jurors MO. REv. STAT. 563(3)(2)(a) (1979), a statute analogous to that overruled by the Supreme Court in Tennessee $v$. Garner. 471 U.S. 1, 11-12 (1985). In Garner, the Supreme Court struck down a Tennessee statute, which like the Missouri statute, allowed the police to use deadly force on a fleeing felon where the suspect was neither armed nor seemingly dangerous. Id. In Garner, the Court held, "Where the officer has probable cause to believe that the suspect poses a threat of serious physical harm, either to the officer or to others, it is not constitutionally unreasonable to prevent escape by using deadly force. Thus, if the suspect threatens the officer with a weapon or there is probable cause to believe that he has committed a crime involving the infliction or threatened infliction of serious physical harm, deadly force may be used if necessary to prevent escape, and if, where feasible, some warning has been given." Id. Thus, the statute that the prosecution provided the grand jurors during the outset of the grand jury proceeding was not only erroneous, it was much more favorable to Wilson. See Nicole Flatow, This Mistake Skewed The Law In Darren Wilson's Favor, Think Progress (Nov. 30,
} 
Wilson, they did provide the grand jurors with Wilson's defense, which was outdated, legally unsound, and yet highly favorable to Wilson.$^{75}$ The prosecution gave the grand jurors a Missouri statue ${ }^{76}$ that the Supreme Court had over-ruled in an analogous case of police force in $1985 .{ }^{77}$ The prosecutor corrected the record two months after providing the grand jurors with the wrong statute and long after Wilson's testimony, allowing the more favorable statute to frame and filter the evidence, including Wilson's testimony. ${ }^{78}$

In yet another display of procedural irregularity, leaving the grand jurors in a deluge of unguided evidence, up until the last day of the proceedings, the prosecutors failed to provide the grand jurors with the Missouri homicide statute, which specifies when the police can use deadly force to effect an arrest and which would have also guided the grand jurors as to which pieces of evidence satisfied the elements. ${ }^{79}$ Typically, a prosecutor will read the applicable statutes at the outset of the grand jury proceedings and explain them in detail in order to guide the jurors as they hear and see the anticipated proof. There again, the prosecution provided the grand jurors with Wilson's defense months before suggesting which crimes he may have committed. ${ }^{80}$

Beyond these procedural irregularities, a lingering pale of suspicion engulfs Saint Louis County Chief Prosecutor Robert McCulloch and his ability to be objective when a white officer has killed a black male. McCulloch himself was a victim of violence. A black man killed McCulloch's father, a white police officer, in the line of duty when McCulloch was 12 years old. ${ }^{81}$ When announcing the grand jurors' no bill, many noted that McCullough delivered his announcement like a defense attorney, giving his closing argument for his client, Wilson, in a jury trial, characterizing and analyzing the witnesses' testimony in the light most favorable to the officer ${ }^{82}$ In addition, "McCulloch has a history of bias in favor of

2014)

https://thinkprogress.org/this-mistake-skewed-the-law-in-darren-wilsons-favor9374d3fba17\#.fwlilvor6.

${ }^{75}$ See Goldwasser, supra note 26, at 41.

${ }^{76}$ You must find "[p]robable cause to believe that he committed the offense, which means that he met all the elements of that offense .... And you must find probable cause to believe that Darren Wilson did not act in lawful self-defense and you must find probable cause to believe that Darren Wilson did not use lawful force in making an arrest. And only if you find those things, which is kind of like finding a negative, you cannot return an indictment on anything or true bill unless you find both of those things. Because both are complete defenses to any offense and they both have been raised in his, in the evidence." Transcript, vol. 24, at 140.

${ }^{77}$ See generally Tennessee v. Gamer, 471 U.S. 1 (1985).

${ }^{78}$ See sources cited supra note 32 and accompanying text

${ }^{79}$ See Transcript, vol. 24, at 135; see also Goldwasser, supra note 26, at 41.

${ }^{80}$ See Goldwasser, supra note 26 , at 42.

${ }^{81}$ Kimberly Kindy, Objectivity of prosecutor in Missouri shooting of Michael Brown is questioned, WASH. PoST (Aug. 15, 2014), https://www.washingtonpost.com/politics/objectivity-of-prosecutorin-missouri-shooting-of-michael-brown-is-questioned/2014/08/15/1 fe20690-24bc-1 le4-958c268a320a60ce_story.html.

${ }^{82}$ Cohn, supra note 59. 
police involved in altercations with black men."83 In 2000, McCulloch mischaracterized testimony in a case involving two black men who police killed after firing 21 shots at them. ${ }^{84}$ "As in the Wilson case, the reasonableness of the officers' use of deadly force was critical." "85 "In the 2000 case, the officers said the two victims were driving toward them, trying to run them down, and McCulloch claimed that all the witnesses corroborated the officers' story." "A "A later federal investigation, however, determined that the car was not moving forward, and that only three of the thirteen officers said the car was moving forward." ${ }^{177}$ Despite this incident, McCulloch ignored the requests of 7,000 residents in and near Ferguson who signed a petition asking that he recuse himself in the Wilson case. ${ }^{88}$

\section{GRAND JURY BACKGROUND}

Given the structural inequality in the grand jury proceedings that privileges the prosecution and distinctively disadvantages defendants, the absence of an indictment in the Wilson proceedings is particularly problematic. In 2010, the most recent year for which there is data, $99.9 \%$ of the time that federal prosecutors presented cases to a grand jury, the grand jury returned an indictment or true bill ${ }^{89}$ According to the Bureau of Justice Statistics, federal prosecutors prosecuted 162,000 federal cases in 2010 , out of which the grand jury declined to indict 11 times..$^{90}$ It is just this kind of success rate that prompted a former chief

${ }^{83} \mathrm{Id}$.
${ }^{84} \mathrm{Id}$.
${ }^{85} \mathrm{Id}$.
${ }^{86} \mathrm{Id}$.
${ }^{87} \mathrm{Id}$.
${ }^{88} \mathrm{Id}$.

${ }^{89}$ Jeffery Fagan \& Bernard E. Harcourt, Professors Fagan and Harcourt Provide Facts on Grand Jury Practice In Light of Ferguson Decision, Columbia Law School (Dec. 5, 2014, 12:00 PM), https://www.law.columbia.edu/media_inquiries/news_events/2014/november2014/Facts-on-

Ferguson-Grand-Jury.

${ }^{90}$ Id. Casselman, supra note 5; see also Bump, supra note 5. Several legal commentators have remarked that in the rare case that grand jurors refuse to return an indictment, the prosecutor may have presented evidence to the grand jury, but did not ultimately seek an indictment. Similarly, many legal commentators suggest that McCulloch could use the grand jury as an investigative body to vet the evidence and to act as a barometer as to whether there was a prosecutable case. There are several responses to this claim. First, Missouri law allows prosecutors to decline prosecution. See Mo. Rev. STAT. $\S \$ 545.010,545.030$ (2016); Mo. Const. art. I § 17; see also Angela J. Davis, The American Prosecutor: Independence, Power, and the Threat of Tyranny, 86 IowA L. REv. 393, 408 (2001) (stating, "The charging decision is arguably the most important prosecutorial power and the strongest example of the influence and reach of prosecutorial discretion."). As a direct result, McCulloch could have declined prosecution. Second, even if he decided in good faith to allow the grand jurors to decide the existence of probable cause, the irregularities in the Wilson grand jury proceedings still remain and stand in stark contrast to standard grand jury operations; thus, the claim that McCulloch merely allowed the grand jury to make the determination as to whether a prosecution should proceed or that McCulloch may use the grand jury for political cover does not explain the irregularities in the Wilson grand jury proceedings or the anti-indictment bias that saturated the process. See Goldwasser, 
judge of the highest New York state court, Sol Wachtler, to remark that prosecutors can "get a grand jury to indict a ham sandwich." 91

The overwhelming success rate for prosecutors in grand jury proceedings is a function of court-sanctioned structural inequality that privileges the prosecution over the defendant. In an opinion, authored by Justice Antonin Scalia, the Supreme Court concretized the structural mechanisms that ensure prosecutorial advantage and success in the grand jury. Writing for the majority, Scalia emphasized that the grand jury is a non-adversarial proceeding, meaning the defendant has no right to be present-let alone testify or be accompanied by a lawyer. ${ }^{92}$ In fact, the suspect or target has no constitutional right to know about the proceedings at all, particularly where the grand jury is serving in its investigative capacity. Only the prosecutor; the witnesses, which the prosecutor has sole discretion to call or not call; the grand jurors; and the transcriptionists are present.

supra note 26, at 42 (stating, "the [Wilson] grand jury presentation was seriously compromised because it was driven from start to finish by a Darren-Wilson-should-not-be-indicted bias so pervasive and powerful that a 'no true bill' was inevitable.").

${ }^{91}$ Sam Howe Verhovek, Wachtler's Reversal of Fortune; Fallout From Chief Judge's Arrest Likely to Extend to Courts, N.Y. TIMES (Nov. 9, 1992), http://www.nytimes.com/1992/1 1/09/nyregion/wachtler-s-reversal-fortune-fallout-chief-judge-sarrest-likely-extend-courts.html. Wilson's case involved a state grand jury, as opposed to a federal one; thus, the federal statistics are not directly comparable to Missouri. Moreover, unlike federal courts, which mandate grand juries for felony cases (see, e.g., Hurtado v. California, 110 U.S. 516, 538 (1884)), Missouri allows prosecutors to decide between proceeding by way of the grand jury or complaint and information. See Mo. REV. STAT. \$ 545.010. If a prosecutor elects to proceed via a complaint and information, the prosecutor files a complaint and engages a preliminary hearing to determine whether there is probable cause to proceed with the adjudication. Mo. R. CRIM. P. 22.09(a). Provided that there is a probable cause finding, the prosecutor then files a formal information. Mo. R. Crim. P. 23.03. Despite these variances in procedure between federal and Missouri cases, and as Wachtler's observation suggests, legal experts agree that it is the rare instance that prosecutors fail to secure an indictment. Casselman, supra note 5 (quoting law professor and grand jury expert Adrew D. Leipold, who stated, "If the prosecutor wants an indictment and doesn't get one, something has gone horribly wrong. It just doesn't happen.").

${ }_{92}$ United States v. Williams, 504 U.S. 36, 49 (1992) (stating, "We have twice suggested, though not held, that the Sixth Amendment right to counsel does not attach when an individual is summoned to appear before a grand jury, even if he is the subject of the investigation."). Like the federal law, in Missouri the target of an investigation, and soon to be defendant (if there is a will to prosecute and there is a probable cause finding), has no right to testify before the grand jury. $19 \mathrm{Mo}$. Prac., Criminal Practice \& Procedure $\S 12: 8$ (3d ed. 2013). Moreover, Missouri essentially follows the same grand jury procedure as the federal system. The Criminal Case: Grand Jury MIssourI BAR, http://www.mobar.org/ThreeColumnPB.aspx?pageid=10547\&id=1359 \#Grand\%20Jury (last visited Oct. 4,2016 ). Aside from the number of jury members, number needed to indict, and amount of time that jurors serve, the grand jury process appears to be work in the same way for both Missouri county courts and U.S. District Courts (MO: 12 jurors serve 3-6 months; 9 needed to indict. Federal: 1623 jurors serve up to 18 months; 12 jurors needed to indict.). Fagan Jeffrey \& Bernard E. Harcourt, Professors Fagan and Harcourt Provide Facts on Grand Jury Practice in Light of Ferguson Decision, Columbia LAw SCHOOL, https://www.law.columbia.edu/media_inquiries/news_events/2014/november2014/Facts-onFerguson-Grand-Jury (last visited Oct. 4, 2016). 
A judge is not present and the jurors deliberate in complete secrecy. It stands to reason that defendants are not entitled to the discovery in grand jury proceedings. The defendant is not entitled to the prosecutor's proof before there has been a charge and an arraignment on an indictment. ${ }^{93}$ Still further, the defendant is not entitled to the exculpatory, Brady, or Giglio materials until at or near the time of trial, which may in fact be after the plea negotiating process. ${ }^{94}$ This is particularly salient because Wilson had access to exculpatory Brady materials as well as Giglio long before any potential trial.

Further cementing the prosecutorial advantage is the inapplicability of the Rules of Evidence in grand jury proceedings. ${ }^{95}$ As a result, prosecutors are free to submit a veritable "hearsay heaven." ${ }^{96}$ Because grand jury proceedings are nonadversarial and the Rules of Evidence do not apply, the prosecutor has sole authority and control over how much evidence is submitted to the grand jury, what evidence is submitted to the grand jury, how that evidence is presented to the grand jury, and the narratives that frame the proof. ${ }^{97}$ As an example, the prosecutor has sole discretion as to which witnesses to call. Because hearsay is permissible, the prosecutor may elect to present the entire case through the testimony of the main investigating officer or agent.

Furthermore, the prosecution, in an effort to indict (provided that there is a desire to indict), can show the grand jurors evidence that may be suppressible in latter proceedings. For example, evidence that violates the defendant's Miranda rights, Fourth Amendment rights against unreasonable searches and seizures, or any other constitutional right is fair game for presentation to the grand jury. ${ }^{98}$ The

${ }^{93}$ FeD. R. CRIM. P. 16(a)(2); see also Brady v. Maryland, 373 U.S. 83, 87 (1963) (stating that due process only violated when favorable evidence withheld after request); U.S. v. Williams, 504 U.S. 36, 51 (1992); State v. Easter, 661 S.W.2d 644, 645 (Mo. Ct. App. 1983).

${ }^{94}$ United States v. Ruiz, 536 U.S. 622, 629, 122 S. Ct. 2450, 2455 (2002).

${ }^{95}$ FED. R. EVID. 1101(d)(2); see, e.g., supra note 43 and accompanying text.

${ }^{96}$ E.g., Williams, 504 U.S. at 50 (1992) (stating that "we declined to enforce the hearsay rule in grand jury proceedings, since that "would run counter to the whole history of the grand jury institution, in which laymen conduct their inquiries unfettered by technical rules." (quoting Costello v. United States, 350 U.S. 359, 364 (1956)). A Missouri grand jury may entertain hearsay evidence. E.g., State v. Brown, 588 S.W.2d 745, 746 (Mo. Ct. App. E.D. 1979); State v. Randolph, 139 Mo. App. 314, 123 S.W. 61 (1909); see also 28 Mo. Prac., Criminal Practice \& Procedure $§ 5: 9$ (3d ed. 2015).

${ }^{97}$ See 19 Mo. Prac., Criminal Practice \& Procedure $\$ 12: 2$ (3d ed. 2015). Because the prosecutor is the sole authority on the amount, kind, and scope of the evidence presented to the grand jury, subject to the probable cause standard, "whole cases are often presented in well under an hour." Goldwasser, supra note 26, at 38; see also, e.g., Transcript of Grand Jury, vol. 2 at 7, State v. Wilson, Sept. 3, 2014, available at https://www.documentcloud.org/documents/1370515-grand-jury-volume-2.html. Wilson's grand jury proceeding, by contrast, lasted for 70 hours over the course of 3 months and met on 25 days. Goldwasser, supra note 26, at 38. Moreover, in the Wilson proceeding, "the prosecution called 60 witnesses, played hours upon hours of video and audio recordings, and presented hundreds of photographs, maps, diagrams, reports and other exhibits." Id.

${ }^{98}$ E.g., Williams, 504 U.S. at 50 (stating that "we rejected the proposal that the exclusionary rule be extended to grand jury proceedings, because of 'the potential injury to the historic role and functions of the grand jury."' (quoting Costello, 350 U.S. at 363)). A Missouri grand jury may entertain 
grand jurors in an effort to charge (again, where there is a desire to charge) can, and often do, see evidence that the petit jurors may never see because the defendant may successfully suppress unconstitutionally obtained evidence before trial, further strengthening the prosecution's discretion, control, and power in the grand jury. ${ }^{99}$

The evidence the prosecution does tender to the grand jury is not subjected to the veritable truth serum of cross-examination or challenge, which is true in the adversarial setting of a trial. The prosecutor can submit as little or as much evidence to the grand jury, subject to the limitation of the burden of proof. Unlike petit juries that decide the ultimate guilt or innocence of a defendant based on the highest standard of proof, beyond a reasonable doubt, ${ }^{100}$ grand jurors merely make a decision to indict a defendant by a much lower standard of proof, "probable cause," which the Supreme Court has defined as "the kind of 'fair probability' on which 'reasonable and prudent [people,] not legal technicians, act."'101 The prosecution not only has sole discretion as to which witnesses to call, but also as a technical matter, the prosecution cannot cross-examine its own witnesses. Crossexamination is left to the adversary, but in grand jury proceedings there is no adversary. As a consequence, prosecutors are not required to cross-examine their own witnesses; rarely do so; and when they do, there is no technical nomenclature for it. This is particularly true because the prosecution does not want, under any circumstances, to create contradictory testimony from its own witnesses. Such contradictory testimony becomes what is known as Giglio materials and the prosecution is constitutionally obligated to turn those materials over to the adversary before trial. Moreover, the defense attorney can use the Giglio materials to cross-examine the prosecutions witnesses.

In a typical accusatory case, the prosecutor calls one or two witnesses, usually the reporting, lead, or main investigating officer. Because the prosecutor single-handedly controls the evidence in the grand jury proceeding, the prosecutor has the discretion to limit the number of witnesses to as few as one as well as the ability to script the question and answers of any given witness prior to the grand testimony, subject to a clear requirement that the testimony be truthful. Typically, the prosecutor limits the testimony of its witnesses in order to avoid creating contradictions and inconsistencies, which lead to impeachment, or Giglio, materials for later use by defense attorneys, if in fact, the grand jury indicts. In more complex cases, a prosecutor may choose to call additional witnesses and to

evidence obtained pursuant to an unlawful search. E.g., Brown, 588 S.W.2d at 746; Randolph, 139 Mo. App. at 314; see also 19 Mo. Prac., Criminal Practice \& Procedure $\S 5: 9$ (3rd ed. 2015).

${ }^{99}$ See Costello, 350 U.S. at 363.

${ }^{100}$ See Williams, 504 U.S. at 51, 69 (making the following two statements in the opinion: "To the contrary, requiring the prosecutor to present exculpatory as well as inculpatory evidence would alter the grand jury's historical role, transforming it from an accusatory to an adjudicatory body." and "A grand jury proceeding is an ex parte investigatory proceeding to determine whether there is probable cause to believe a violation of the criminal laws has occurred ....").

${ }^{101}$ Florida v. Harris, 133 S.Ct. 1050, 1055 (2013) (quoting Illinois v. Gates, 462 U.S. 213, 235 (1983)). 
submit forensic proof. In order to protect the integrity of the witness's testimony, the prosecutor may direct the witness to refrain from talking to anyone else about the case without informing the prosecution. The prosecutor can also prepare a written statement for the witness to read to the grand jury; direct the witness to review the statement for complete and total accuracy before testifying in the grand jury; have the witness review the statement with an attorney, for even more accuracy; and then allow the witness to read the statement to the grand jurors. After the witness has read the statement, the prosecution can ask the grand jury foreperson to excuse the witness; ask the grand jurors if they have any questions of the witness; meet the witness outside the presence of the grand jurors; ask the witness the question; and have the witness return to answer the question if the prosecutor is satisfied that the witness can answer the question without jeopardizing the case as well as the witness's credibility. If the question bears no relevance as to the probable cause determination, the prosecution, which is the legal advisor to the grand jury, can inform the grand jury that the question lacks relevance or materiality. In sum, the prosecution has a constitutionally prescribed arsenal to protect its witnesses, the integrity of witness testimony, and the viability of the prosecution.

Most importantly, with respect to the structural inequality favoring the prosecution and disfavoring the defendant, the Supreme Court has consistently held that the prosecution is not required to present exculpatory information to the grand jury. ${ }^{102}$ In explaining the reasoning behind the absence of exculpatory materials in grand jury proceedings, Justice Scalia writing on behalf of the Court stated:

It is axiomatic that the grand jury sits not to determine guilt or innocence, but to assess whether there is adequate basis for bringing a criminal charge. That has always been so; and to make the assessment it has always been thought sufficient to hear only the prosecutor's side. As Blackstone described the prevailing practice in 18th-century England, the grand jury was only to hear evidence on behalf of the prosecution, for the finding of an indictment is only in the nature of an enquiry or accusation, which is afterwards to be tried and determined. So also in the United States. According to the description of an early American court, three years before the Fifth Amendment was ratified, it is the grand jury's function not "to enquire ... upon what foundation the charge may be denied, or otherwise to try the suspect's defenses, but only to examine upon what foundation the charge is made by the prosecutor." As a consequence, neither in this country nor in England has the suspect under

\footnotetext{
${ }^{102}$ Missouri law does not require the submission of exculpatory materials to the grand jury. E.g., State v. Easter, 661 S.W.2d 644, 645 (Mo. Ct. App. 1983); see also Mo. Prac., Criminal Practice \& Procedure $\S 5: 9$ (3rd ed. 2015).
} 
investigation by the grand jury ever been thought to have a right to testify or to have exculpatory evidence presented. ${ }^{103}$

Considering the Supreme Court's reasoning and pronouncements, it is absolutely incredible that Wilson not only testified before the grand jury, but he was allowed to provide his story over the course of four hours without cross examination ${ }^{104}$ or challenge (unlike the other witnesses); the prosecutors used other evidence, including forensic proof to corroborate ${ }^{105}$ his claims; and the prosecution used other evidence, including witness testimony to frame Wilson's alleged fears, particularly about Brown's dangerousness, all of which provided legal justification for Wilson's killing of Brown. As Goldwasser argues, the prosecution also called Wilson as a witness during the initial phases of the proceeding - the ninth out of 60 witnesses - allowing his story to guide their apprehension of the remaining presentation of proof particularly in a deluge of evidence without guidance in the form of a proposed indictment or the Missouri homicide statute. ${ }^{106}$ Seven of the eight witnesses that testified before Wilson had either spoken to Wilson about the event or had interviewed someone that had spoken to Wilson. The prosecution asked each of the seven about the salient aspects of Wilson's defense, particularly that Brown had assaulted him while he was sitting in his $\mathrm{car}^{107}$ Wilson chased Brown because Brown would assault or harm someone else; ${ }^{108}$ and that Brown turned around, charged at Wilson, and caused Wilson to fear for his life. ${ }^{109}$ By the time Wilson completed his testimony, the prosecution had called nine witness, including Wilson, that substantiated Wilson's defense, which the prosecution had based on an unconstitutional law more favorable to Wilson.

The prosecution not only submitted the exculpatory materials to the grand jury, but Wilson's defenses framed the evidence. Moreover, Wilson had access to the state's discovery before he testified. Despite the myriad means for protecting

103 Williams, 504 U.S. at 51-52 (internal punctuation and citations omitted).

${ }^{104}$ As a technical matter, the prosecution cannot cross-examine its own witnesses. Cross-examination is left to the adversary, but in grand jury proceedings there is no adversary. This is not to say, however, that the prosecutors had to refrain from attempting to create inconsistent statements that could later be used to impeach Wilson.

${ }^{105}$ As an example, after Wilson testified that Brown started pummeling him while he was armed, uniformed, and seated in police issued SUV; that Brown paused long enough to pass Johnson the cigarillos; and that Brown responded to Wilson with an insulting epithet after Wilson pointed a gun in his face, the prosecutor retrieved several exhibits, one of which was a picture of Wilson's face showing swelling. Testimony, vol. 5 , at 220 . Not only did the prosecutor corroborate Wilson's claim, but failed to subject him to any questioning concerning the questionable probability of an unarmed youth pummeling an armed, uniformed officer, seated in a police issued SUV, pausing to give a package to his companion; responding to a gun pointed in his face with an epithet; and the absence of severe bruising after being punched by Hulk Hogan.

${ }^{106}$ Goldwasser, supra note 26, at 42.

${ }^{107}$ Transcript, vol. 5 , at 32.

${ }^{108}$ Transcript, vol. 5, at 33-34.

${ }^{109}$ Goldwasser, supra note 26, at 43. 
witness testimony, the prosecution thoroughly challenged its own witnesses, concretely damaging their credibility for any future proceeding, in sharp contrast to its delicate treatment of Wilson. Moreover, as Goldwasser compellingly argues, in presenting all the evidence, including the unconstitutionally required exculpatory proof, the prosecution gave the grand jurors evidence "that no prosecutor who was actually trying to help them do their job - that is, trying to help them determine whether there was probable cause to believe that Darren Wilson had committed a crime when he killed Michael Brown - would ever present." ${ }^{\prime 10}$ In sum, the prosecution presented Wilson's case-in-chief without the benefit of challenge from an adversary. Instead of prosecuting Wilson, the prosecutors convicted Brown through Wilson's case-in-chief. Moreover, the prosecution presented a defense for Wilson far outstripping anything a defense attorney could have provided Wilson in its case in chief at trial.

\section{STRUCTURAL IMPEDIMENTS TO INDICTING WHITE OFFICERS WHO KILL BLACK PEOPLE ${ }^{111}$}

Despite the structural advantage prosecutors enjoy in grand jury proceedings, indictments of police officers who kill black people are more the exception than the rule, which is the case in Ferguson. Criminologist Philip M. Stinson indicates that only 41 officers faced murder or manslaughter charges from on-duty shootings over a seven-year period, which ended in $2011 .{ }^{112}$ Over that same period, legal scholars Jeffery Fagan and Bernard E. Harcourt note that the FBI received reports of 2,600 justifiable homicides from police departments across the country. From 1976 to 2012, according to FBI statistics, St. Louis County officers fatally shot 186 people. ${ }^{113}$ Professors Fagan and Harcourt go on to report, "Law enforcement reported self-defense ('felon attacked officer') in 77 of these incidents $(41.3 \%) .{ }^{114}$ In another $15(8.1 \%)$, the killings occurred when the 'felon attacked a fellow officer." "'I5 From 1990, one year before McCulloch became the St. Louis County Prosecuting Attorney, through 2012, officers fatally shot 112

\footnotetext{
${ }^{110} I d$ at 40.

${ }^{111}$ It is imperative to note that the following analysis would look markedly different where a black male officer killed an unarmed female for example. The grand jury inversion that occurs when white officers kill black people lacks application to the latter.

112 James C. McKinley Jr. \& Al Baker, A System, With Exceptions, That Favors Police in Fatalities, N.Y. Times (Dec. 8, 2014), http://www.nytimes.com/2014/12/08/nyregion/grand-juries-seldomcharge-police-officers-in-fatal-actions.html?_r=0.

113 Jeffery Fagan \& Bernard E. Harcourt, Professors Fagan and Harcourt Provide Facts on Grand Jury Practice In Light of Ferguson Decision, COlumBia Law SchoOL (Dec. 5, 2014, 12:00 PM), https://www.law.columbia.edu/media_inquiries/news_events/2014/november2014/Facts-on-

Ferguson-Grand-Jury.

114 Id.

${ }^{115} \mathrm{Id}$.
} 
civilians times; $80(71.4 \%)$ of the victims were Black. ${ }^{116}$ From 2005 to 2012 , officers fatally shot 53 civilians; thirty-seven $(69.8 \%)$ of the victims in those shootings were Black. During McCulloch's reign, which began in 1991, 33 police officers have been criminally prosecuted, 20 have been convicted, and 5 cases remain pending. ${ }^{117}$ On at least four occasions, prosecutors presented cases involving police killings of citizens while on the job, where the grand jury failed to return an indictment. ${ }^{118}$ Brown is the fifth case in which the officer was not indicted. ${ }^{119}$ There are three main reasons that police shooting cases so rarely lead to indictments, despite the fact that grand jury indictments in general are overwhelmingly successful: biased investigations, prosecutions stemming from an inherent conflicts of interests, and the collective bargaining power of police unions.

\section{A. Biased Investigation and Prosecution: Inherent Conflict of Interest}

Prosecutors and police are part of the single knit unit of law enforcement: They form the same side of the adversarial wall. Generally, police ensure the integrity of the investigation, while prosecutors secure the merits of the adjudication. The two work in complete tandem. Not infrequently prosecutors, officers, and agents will refer to one another as "brother," evincing a sense of fraternity, kinship, bonding, shared cause, and mutual destiny. Prosecutors and officers are mutually dependent and frequently operate on a sense of fraternity, trust, and kinship--each relying on the integrity of the other in order to protect and ensure sound investigations and prosecutions. Prosecutors not only trust the police to bring them sound cases, free of unconstitutionally derived evidence, like forced confessions, but prosecutors must rely on officers' integrity, ability to testify about the investigation and evidence, and credibility to withstand cross-examination. Prosecutors often engage meticulous efforts to protect the integrity of their cases, including preparing their officers for both direct examination and crossexamination before every hearing and in particular before trial. Again, prosecutors engage great efforts and pains to preserve the integrity of their witness' testimony through preparation before testifying and clear avoidance of creating impeachment or Giglio materials. Officers are vital, if not indispensable, parts of a prosecution. The mutual dependency between police and prosecutors presents an inherent conflict of interest when prosecutors prosecute their "brothers" accused of excessive use of force, likened to members of the same family prosecuting one another. Similar problems adhere when police investigate their colleagues.

\footnotetext{
${ }^{116} \mathrm{Id}$.

117 Id. (citing Heather Cole, Background Check: Looking at McCulloch's Prosecution History, MISSOURI LAWYER'S WEEKLY, Sept. 8, 2014, available at http://molawyersmedia.com/2014/09/08/background-check-looking-at-mccullochs-prosecutionhistory/).

${ }^{118} I d$.

${ }^{119} \mathrm{Id}$.
} 
The prime example of this in the case of Wilson and Brown is how Wilson's supervising officer allowed Wilson to leave the murder scene without being questioned or processed for evidence, including allowing Wilson to return to the police station unescorted, to wash blood from his hands, and to bag his own murder weapon in an evidence bag. It is inconceivable that a civilian shooter would receive such privilege under any circumstances. This points to an inescapable problem in the investigation of Wilson, the inherent conflict of interests where police officers investigate other officers, and a structural impediment in police shootings of black persons. In criminal investigations, particularly police shootings, the suspect needs time to, as Law Professor Kenneth Lawson states, "get his story straight ..." before being interrogated about the details of the crime, especially where the officer needs to cast the black victim as the villain and to frame the shooting as carefully calibrated with a justifiable and reasonable use of deadly force, for example, claiming the victim reached at his waistband for a what appeared to be a gun. ${ }^{120}$ Unlike other homicide suspects, officers are given

\footnotetext{
${ }^{120}$ Kenneth Lawson, Police Shootings of Black Men and Implicit Racial Bias: Can't We All Just Get Along, 37 U. HAw. L. REV. 339, 362 (2015); see also Saul M. Kassin et al., Interviewing Suspects: Practice, Science, and Future Directions, 15 LEGAL \& CRIM. PSYCHOL. 39, 42 (2009). It should also be noted that " $[\mathrm{t}]$ he prosecutor asked witness after witness if it seemed as if Mr. Brown were reaching for a weapon ...." Bosman, supra note 61. In several unarmed shooting cases, where the officer needs to cast the black victim as the villain and to describe the shooting as carefully calibrated with a justifiable and reasonable use of deadly force, officers frequently claim that the victim reached at his waistband for a what appeared to be a gun. Kenneth Lawson, Police Shootings of Black Men and Implicit Racial Bias: Can't We All Just Get Along, 37 U. HAw. L. REv. 339, 362 (2015); Wilson told the grand jury that he thought Brown was reaching at his waistband for a gun. Moreover, implicit bias is a useful frame for understanding not only the killing of Michael Brown but other black men as well. In the case involving Oscar Grant, an unarmed black man at the Fruitvale BART station, Officer Johannes Mehserle shot Grant in the back from point-blank range where Grant was lying face down and was physically restrained by another officer. A grand jury charged Mehserle of seconddegree murder, but a petit jury only convicted him of involuntary manslaughter. The involuntary manslaughter conviction may have reflected the jury's acceptance of two of Mehserle's claims: "first, that he thought Grant was reaching for a gun, and second, that he mistook his own gun ... for a Taser ...." Implicit Racial Bias Across The Law 9 (Justin D. Levinson \& Robert J. Smith eds., 2012). It is clear that implicit bias has the power to create a gun where none exists or to deny a gun where it in fact exists. In the case of Levar Jones, Officer Shawn Groubert asked Jones for his license and registration, while Jones was standing immediately outside of his car. When Jones turned to reach inside his car for the items Groubert had just requested, Groubert responded with gunfire, hitting Jones. Later in explaining the incident to his supervisor, Groubert claimed that Jones was continuing to advance toward him with something black in hands, a claim negated by the video coverage. All In With Chris Hayes: Chilling New Audio Uncovered from SC Shooting Tape, (MSNBC television broadcast Sept. 29, 2014), available at http://www.msnbc.com/all-in/watch/chilling-new-audiofrom-sc-shooting-tape-335257667981 (showing Chris Hayes interviewing Phillip Atiba Goff, Assistant Professor of Psychology, University of California, Los Angeles). St. Anthony police officer Jeronimo Yanez, who is Latino, fatally shot Philando Castile during a traffic stop. His girlfriend, who was in the car along with her small child, claims "Castile was shot while reaching for his ID after telling the officer he had a gun permit and was armed. Yanez's attorney has said the officer reacted after seeing a gun, and that one of the reasons he pulled Castile over was because he thought he looked like a "possible match' for an armed robbery suspect." How Philando Castile Told
} 
substantial time and opportunity to "get their story right," 121 particularly where the officer must reconcile his narrative with other evidence, including dispatch recordings; video footage; dashboard camera and body camera recordings; forensics tests; autopsy reports that document bullet entries and exits; and other witnesses' accounts. Typically, suspects do not have access to this evidence before being initially interviewed nor do they have an attorney present during the initial interview, unlike Wilson who had access to the evidence as well as attorneys during all of his interviews, except his initial questioning by his supervisor at the murder scene, which was not documented, and Wilson's grand jury appearance, where he did not have counsel in the grand jury room itself. Still further, defendants are entitled to discovery shortly after an arraignment. The discovery to which defendants are entitled is much narrower in scope than all of the evidence. In particular, defendants are not entitled to exculpatory materials until at or near the time of trial. It is beyond the pale for a defendant to have all of the evidence before an indictment has issued, let alone before providing testimony to a grand jury.

Typically, in non-officer homicide investigations, police aggressively attempt to interrogate the suspect immediately, keeping the suspect isolated, particularly from co-conspirators and defense attorneys. ${ }^{122}$ Police also attempt to obtain a documented statement from the suspect and witnesses, leaving no time for the suspect to concoct a defense, consult an attorney, or coordinate a narrative or false truth. ${ }^{123}$ Yet law enforcement rarely enforces these protocols in the aftermath of officer shootings, and they were not followed in the specific case of Wilson. As Lawson demonstrates, the increase of time between the homicide and the interrogation provides the suspect with the greatly desirable resource of time to create a narrative that exculpates the suspect, cementing the need to obtain confessions from suspects as close to the time of the homicide, subject to constitutional protections, of course. ${ }^{124}$

Despite these standard investigative procedures, much like the standard grand jury protocols, when law enforcement investigates excessive use of force cases against black victims, an inversion occurs-investigators compromise investigations, "by investigators' apparent bias in favor of clearing the officer

Officer About Gun Critical in Investigation, CHI. TrIB. (Jul. 14, 2016, 8:21PM), http://www.chicagotribune.com/news/nationworld/ct-philando-castile-concealed-carry-20160714story.html. In each of these cases, implicit bias not only has the capacity to create a gun where none exists, but the claim alone resonates for persons listening to the officers' narrative, much like an implicit bias dog whistle.

121 Lawson, supra note 120 , at 362 . This is particularly true in those states that have a Law Enforcement Bill of Rights where an officer is not required to interview after a fatal shooting, 10 days for example in Baltimore, Maryland. Paul Butler, The Police Officers' Bill of Rights Creates a Double Standard, N.Y. Times (June 27, 2015, 9:13PM), http://www.nytimes.com/roomfordebate/2015/04/29/baltimore-and-bolstering-a-police-officersright-to-remain-silent/the-police-officers-bill-of-rights-creates-a-double-standard.

${ }^{122}$ See Lawson, supra note 120 , at 362.

${ }^{123} \mathrm{Id}$.

${ }^{124} \mathrm{Id}$. 
instead of objectively pursuing all of the available facts." 25 Allowing Wilson to leave the murder scene without being interviewed by the investigative team; without being processed for evidence, with literal blood on his hands; and without taking a documented statement paradigmatically exemplifies investigator bias and the realizations of an inherent conflict of interest where officers investigate their own.

\section{B. Police Unions and Their Collective Bargaining Agreements}

In addition to the inherent conflict of interest where law enforcement investigates and prosecutes itself as well as investigator bias in that endeavor, police unions present another structural impediment to both investigating and prosecuting white officers who kill Blacks. With excessive use of force cases, police officers frequently benefit from additional safeguards in their collective bargaining agreements between their police unions and employers. ${ }^{126}$ According to the International Association of Chiefs of Police's Officer-Involved Shooting Guidelines, "Whenever possible, officers should be educated on the protocol of the investigation as well as any potential actions by the media, grand jury, or review board prior to any formal investigative interviews." 127 Unlike a typical homicide, an officer is frequently allowed to meet with an attorney or union representative prior to being questioned, and the interview may not even occur on the day of the murder. ${ }^{128}$ An obvious contrast exists, where in typical homicide cases, officers attempt to obtain statements from suspects immediately, preferably before they meet with an attorney, subject to Miranda. ${ }^{129}$ Such was the case with Wilson. In addition to being allowed to leave the murder scene without being interviewed by anyone other than his supervisor, who never documented the discussion, or being processed by anyone at the murder scene, Wilson was not "officially" interviewed until the next day following the shooting, when he appeared with his attorney. ${ }^{130}$

\section{THE CENTRALIZED ROLE OF RACE: IMPLICIT BIAS MADE EXPLICIT}

\footnotetext{
${ }^{125}$ Id. (quoting Civil Rights Division, U.S. Dept. Of Justice, Investigation Of The Cleveland Division OF POLICE 34 (Dec. 4, 2014), available at https://www.justice.gov/sites/default/files/crt/legacy/2014/12/04/cleveland_findings_12-4-14.pdf).

${ }^{126}$ See Police Psychological Services Section, Int'l Assoc. of Chiefs of Pollice, OfficerINVOLVED SHOOTING GUIDELINES 4 (2013), available at http:/www.theiacp.org/portals/0/documents/pdfs/Psych-OfficerInvolvedShooting.pdf; see also Lawson, supra note 120 , at 362-63.

127 OfFICER INVOLVED SHOOTING GUIDELINES, supra note 126, at 4-5.

${ }^{128}$ Lawson, supra note 120 , at 363.

${ }^{129} \mathrm{Id}$.

${ }^{130}$ Memorandum, supra note 11 , at 12 .
} 
In addition to the structural impediments to indicting white officers who kill unarmed black people, the centrality of white heteropatriarchy as manifest in implicit bias further explains the unusual grand jury dynamics in the Wilson proceeding. White heteropatriarchy, like all operations of systemic power, whether raced, gendered, classed, intersectional, or multiconscious, is omnipresent and entrenched, yet it often remains invisible, marked (or unmarked as it were), as inevitable, natural, justified, perfectly acceptable, and seamless. ${ }^{131}$ Implicit bias achieves the legitimacy of "evidence" through hegemonic performances of law, in which the biased narratives of police officers are introduced as incontrovertible, even when they are not supported by facts. In so doing, the white supremacist and heteropatriarchal assumptions of implicit bias achieve legitimization through obfuscation, invisibility, and inevitability. In summarizing the role of the law as a legitimating function of dominance and supremacy, Crenshaw states:

Law is an essential feature in the illusion of necessity because it embodies and reinforces ideological assumptions about human relations that people accept as natural or even immutable. People act out their lives, mediate conflicts, and even perceive themselves with reference to the law. By accepting the bounds of law and ordering their lives according to its categories and relations, people think that they are confirming reality - the way things must be. Yet by accepting the view of the world implicit in the law, people are also bound by its conceptual limitations. Thus conflict and antagonism are contained: the legitimacy of the entire order is never seriously questioned. ${ }^{132}$

Implicit bias research demonstrates that pathology perpetually clings to the black body and innocence melds with the white body, such that, even where the white body is engaged in treachery, it is perceived as innocent and where the black body is engaged in innocence, it is perennially pathological. Even when a white police officer murders an unarmed black youth in broad daylight on a summer day in the middle of a well-traversed public street, implicit bias, which saturates both public and legal discourses, frame the white shooter as valiant and the black victim as demonic.

As explained in the introduction, implicit bias is a narrative that explains the meaning we attach to objects and bodies in our unfiltered and unregulated ("unconscious") mind. ${ }^{133}$ "It is simply a form of categorization"134 that affects "perception, interpretation, encoding, retention, and recall of information about

\footnotetext{
${ }^{131}$ See Michel Foucault, The History of Sexuality: Volume 1: AN Introduction 86 (Robert Hurley trans., Random House 1978) (suggesting that "power is tolerable only on condition that it mask a substantial part of itself. Its success is proportional to its ability to hide its own mechanisms."). ${ }^{132}$ Crenshaw, supra note 6, at 1351-52.

${ }^{133}$ See supra note 20 and accompanying text.

134 Linda Hamilton Krieger, The Content of Our Categories: A Cognitive Bias Approach to Discrimination and Equal Employment Opportunity 47 STAN. L. REv. 1161, 1187-88 (1995).
} 
other people."135 Using cognitive tests, neuroscientists have gathered empirical evidence on implicit bias by measuring the time it takes to make associations between objects and bodies. Such tests typically assess at least two types of association: schema consistent pairings (when the objects and associations being paired obviously "match"), and schema inconsistent pairings (when people are asked to match objects and meanings that don't typically connect). Using these cognitive tests, scientist can capture the time it takes to associate dangerousness, suspiciousness, and villainy with black bodies and goodness, righteousness, and innocence with white bodies; they can also measure the reverse - the difficulty people have when asked to associate blackness with goodness and whiteness with danger. ${ }^{136}$

Unlike explicit bias, institutional racism, or structural racism, implicit bias reflects nanosecond associations that are allegedly unintentional and unconscious. For example, in one form of implicit bias testing, test-takers were given "whitesounding" names, and were asked to pair them with good things, like goodness, kindness, hard-working, thrifty, and moral. ${ }^{137}$ The same test-takers were given "black-sounding" names, like Ebony or Sharonda, and asked to pair those names with unpleasant ideas like evil, immoral, unchaste, and criminal. Their response times were relatively quick. ${ }^{138}$ Then the test-takers are asked to make the schemainconsistent pairings, and to associate the black names with goodness and white bodies with evil. The response times were much slower. ${ }^{139}$ Of over 14 million Implicit Association Tests (IATs) taken, upwards of 75 percent of test takers demonstrate implicit bias in favor of whites. ${ }^{140}$ Although at much lower rates, Black people also demonstrated implicit bias with 40 percent of test-takers demonstrating favor for Whites. ${ }^{141}$ Given the sheer prevalence of implicit bias as captured by the IAT, there is an argument to be made that racial hostility is

\footnotetext{
${ }^{135} \mathrm{Id}$. at $1188-89$.

${ }^{136}$ See ImPLicit RaCial Bias Across The LaW, supra note 120, at 9-10. Implicit bias testing operates through cognitive psychology "priming," as seen in dog whistling: It is a stimulus that has an effect on an unrelated task that triggers associative networks, which can include stereotypes and can influence decision-making as well as behavior. $I d$. at 10 .

${ }^{137}$ See Anthony G. Greenwald et al., Measuring Individual Differences in Implicit Cognition: The Implicit Association Test, 74 J. PERSONALITY \& SOC. PSYCHOL. 1464, 1473-74 (1998), available at http://faculty.washington.edu/agg/pdf/Gwald_McGh_Schw_JPSP_1998.OCR.pdf.

${ }_{138}$ See id.

${ }^{139}$ See id. at 1474.

${ }^{140}$ Cynthia Lee, A New Approach to Voir Dire on Racial Bias, 5 U.C. IRVINE L. Rev. 843, 860 (2015) (citing Mahzarin R. Banajl \& ANTHONy G. Greenwald, Blindspot: Hidden Biases Of Good PEOPLE 69 (2013)).

${ }^{141}$ Lee, supra note 140 , at $118 \mathrm{n}$. 105 (stating "that Banaji and Greenwald's research found that about forty percent of African Americans have a pro-White bias, forty percent have a pro-Black bias, and twenty percent are neutral").
} 
omnipresent and ubiquitous. ${ }^{142}$ Moreover, far from being an isolated thought, ${ }^{143}$ if left uncontested, it may be a permanent filter of the mind, through which we see our reality and in particular evidence, most especially the body of proof.

\section{A. Cognitive Tests and Officer-Involved Shootings}

In addition to the prevalence of implicit bias in general terms, several implicit bias tests capture associations that are relevant to how we see evidence in the particular cases of officer-involved shootings such as that of Michael Brown. Implicit biases may have worked against Brown on numerous intersectional axes: the combination of his age, race, and gender; his presumed criminality, lunacy, and imperviousness to pain; and his location in a "bad neighborhood" of St. Louis; while simultaneously such biases would have worked in favor of Wilson: the combination of his age, race, and gender, his presumed integrity as a police officer; his presumed innocence and goodness, particularly when juxtaposed and valued against the demonry of Brown; and his perceived vulnerability, particularly to crime and black maleness.

\section{B. Aggression, Children, Race, and Racially Disparate Punishment}

The association of villainy with blackness and valor with whiteness occurs at an early, formative stage. ${ }^{144}$ Researchers have demonstrated that when children

${ }^{142}$ Farley, supra note 2, at 486-87. (Farley's keen insights into the ubiquity of race bear repeating: "Race is not reducible to economics or politics. Indeed, it is akin to sexuality: When taxicab drivers, and store owners, bankers, farmers, Christian ministers, doctors, politicians, patients in mental hospitals and their attendants, writers, university presidents, union members and mill owners, garbage collectors and Rotarians, rich and poor, men and women, unite in common worship and common fear of one idea we know it has come to hold deep and secret meanings for each of them, as different as are the people themselves. We know it has woven itself around fantasies at levels difficult for the mind to touch, until it is a part of each man's internal defense system, embedded like steel in his psychic fortifications. And, like the little dirty rag or doll that an unhappy child sleeps with, it has acquired inflated values that extend far beyond the rational concerns of economics and government, or the obvious profits and losses accruing from the white-supremacy system, into childhood memories long repressed. The meanderings of the colorline do not admit of precise analysis. In the words of William James, 'something always escapes.' However, we neglect or deny the colorline's ability to escape precise analysis at our peril. The naive hope of the Civil Rights Movement that more information about subaltern suffering would change the hearts and minds of a colorlined nation fades even further if we think of race as a form of pleasure. The suggestion that racism in today's post-civil rights era is unconscious is secondary if we think of race as a practice people enjoy, as a form of pleasure.").

${ }^{143}$ See IMPLICIT RACIAL BIAS ACROSS THE LAW, supra note 120, at 19-21. Several predictive validity tests dispel the myth that implicit bias is a mere thought unconnected to action. (discussing the affect of implicit bias on economic discrimination, the provision health care services, and employment discrimination).

144 See generally Sagar HA \& Schofield JW, Racial and Behavioral Cues in Black and White Children's Perception of Ambiguously Aggressive Acts, J. PERS. SOC. PSyCHOL., Oct. 1980. 
of different races are engaged in the exact same conduct, aggression is perceived according to the race of the child. ${ }^{145} \mathrm{~A}$ slight push, for example, is seen as much more aggressive when perpetrated by a black child as opposed to a white child. ${ }^{146}$ Researchers tested sixth graders and showed them a series of pictures, where, for example, one shoves another boy in the hallway, or one child borrows a pencil from another child. ${ }^{147}$ When the sixth graders were shown pictures, of black children engaged in these behaviors, they were more inclined to see these behaviors as aggressive, than when white children were engaged in the same conduct. ${ }^{148}$ When the person in the picture was black rather than white, the behavior was seen more mean and threatening to the participants. ${ }^{149}$

\section{Juvenile Justice}

Scholars have used implicit bias research to capture the omnipresence of white heteropatriarchy and its entrenchment in the criminal justice system, particularly with studies that assess how the public and law enforcement perceive racialized dangerousness, suspiciousness, and threats. ${ }^{150}$ "The most comprehensive studies of racial bias in the exercise of prosecutorial and judicial discretion involve the treatment of juveniles." 151 These studies demonstrate "that youth of color are more likely to be arrested, detained, formally charged, transferred to adult court, and confined to secure residential facilities than ..." similarly situated Whites. ${ }^{152}$ The probability that implicit bias will impact prosecutorial discretion is especially acute in drug cases, where virtually identical behavior is susceptible to a wide variety of interpretations and responses depending on the race of the transgressor and where the media imagery and political discourse surrounding these cases has been so thoroughly racialized. Implicit bias determines whether a youth is perceived as a dangerous drug-dealing thug, as opposed to a

${ }^{145} \mathrm{Id}$.
${ }^{146} \mathrm{Id}$.
${ }^{147} \mathrm{Id}$.
${ }^{148} \mathrm{Id}$.
${ }^{149} \mathrm{Id}$.

150 See Implicit RaCial Bias ACross The Law, supra note 120, at 22-24 (discussing implicit bias impact on judicial decision making, the probative value of evidence, racialized presumptions of innocence).

151 Michelle Alexander, The New Jim Crow: Mass Incarceration in the Age of ColorblindNESS 118 (The New Press, 2010).

152 Id; see also Thomas Rudd, Racial Disproportionality In School Discipline: Implicit Bias Is Heavily Implicated, KIRWAN INST. FOR THE STUDY OF RACE AND ETHNICITY, (Feb. 2014), available at http://kirwaninstitute.osu.edu/racial-disproportionality-in-school-discipline-implicit-bias-isheavily-implicated/ (citing a "2010 finding that over $70 \%$ of the students involved in school-related arrests or referred to law enforcement were Hispanic or Black"). It should also be noted that these outcomes are not necessarily the result of implicit bias, but may also be caused by institutional or structural racism or explicit bias. 
"good kid" who was merely experimenting with drugs, selling to a few of his friends, having a good time, and just being young.

\section{Facial Bias}

In another test measuring the nanosecond association of blackness with criminality and demonry and whiteness with goodness and innocence, "a 2004 study presented 182 police officers with Black and White faces." "153 The test questioned officers as to which face "looked criminal."154 In response, "Black faces looked more criminal to police officers, and the darker the face, the more criminal the officer tended to think the person was."155

\section{E. Black People as Animal Bias}

In a study analyzing black dehumanization or Pseudospeciation, Phillip Goff tested the time it took for test takers to detect "a degraded image of an ape that came into focus over a number of frames" when primed with a black or white face. ${ }^{156}$ When primed with consciously undetectable black faces, test takers were able to identify the ape in fewer frames. When primed with a consciously undetectable white face, test takers required more frames to recognize the ape. In a similar study, Goff exposed test participants to a video of police beating a black suspect, when primed with images of apes, test takers were more inclined to interpret the beating as "deserved" and "justified."157

\section{F. Shooter Bias}

This readiness to perceive "dangerousness" as attached to a black body, or "blackness" as the embodiment of evil, is particularly problematic in shooter bias simulations. In shooter bias research, scientists have developed video simulations to measure the effect of race on the decision to shoot. In this simulation, test-takers are shown a number of white and black male images and incentivized to shoot the person holding a gun, as opposed to the person holding an innocent object like a flashlight or wallet. In addition, there are time pressures added to the simulation

${ }^{153}$ Lawson, supra note 120, at 361 (citing Jennifer L. Eberhardt, Seeing Black: Race, Crime, and Visual Processing, 86 J. Personality \& SOC. Psychol. 876, 888 (2004)).

${ }^{154} I$ Id.

${ }^{155} \mathrm{Id}$.

${ }^{156}$ Implicit RaCial Bias Across The LAw, supra note 120, at 49 (citing Phillip Atiba Goff et al., Not Yet Human: Implicit Knowledge, Historical Dehumanization, and Contemporary Consequences, 94 J. Personality \& SOC. PSYCHOL. 292, 304-05 (2008)) (analyzing implicit bias through in criminal cases reflecting association of Blacks with apes and positing that the dehumanizing effect of these historical references influences perception and judgment).

${ }^{157}$ Implicit RaCial Bias ACross The LAW, supra note 120, at 50. 
such that testers have little time to discern who is holding a gun or a flashlight. Point penalties ensue for shooting persons holding innocent objects. Overwhelmingly, test-takers "more quickly detected guns when primed with a Black face than when primed with a White face." Overwhelmingly, test-takers erroneously saw a gun "more often when the face was black than when it was white."158

In another experiment, Joshua Correll specifically tested the shooter bias of police officers. ${ }^{159}$ Although the officers showed greater accuracy in detecting the presence of a weapon than civilian test takers, the officers still demonstrated "robust racial bias in the speed with which they made shoot/don't-shoot decisions." 160 Officers more quickly shot at armed black suspects than armed white suspects. ${ }^{161}$ Another study throughout the United States found that officers exhibited similar reaction time bias towards Latinas/os (Latinix) relative to Whites and Asians. ${ }^{162}$

\section{G. Predictive Validity: Implicit Bias Affects Material Reality}

As innocence, deniability, and righteousness continue to cling to white heteropatriarchy, some have questioned whether implicit bias is merely an idea, having no effect on action, decision-making, and behavior. Predictive validity tests, however, establish a direct correlation between implicit bias and action. ${ }^{163}$ One study measured the effect of implicit bias on a physician's treatment decisions, specifically whether doctors held racially discriminatory implicit bias against Blacks and whether this bias influenced their care to patients. ${ }^{164}$ During the study, researchers presented 300 emergency room and internal medicine physicians with a vignette asking them to diagnose and treat hypothetical patients, who were depicted as either black or white. ${ }^{165}$ The doctors were also given several IATs. ${ }^{166}$ The results demonstrated that the doctors favored white patients to black patients and their implicit bias predicted whether they would recommend thrombolysis

\footnotetext{
${ }^{158}$ Lee, supra note 140, at 1557-1610 (citing B. Keith Payne, Weapon Bias: Split-Second Decisions and Unintended Stereotyping, 15 CURRENT DIRECTIONS PSYCHOL. SCI. 287, 287 (2006)).

${ }^{159}$ Joshua Correll, et al., Across the Thin Blue Line: Police Officers and Racial Bias in the Decision to Shoot, 92 J. Personality \& SOC. PSYCHOL. 1006 (2007).

${ }^{160}$ See Joshua Correll, et al., Across the Thin Blue Line: Police Officers and Racial Bias in the Decision to Shoot, 92 J. Personality \& Soc. Psychol. 1006, 1020 (2007).

${ }^{161}$ Id. at 1007.

162 Melody S. Sadler, Joshua Correll, Bernadette Park \& Charles M. Judd, The World Is Not Black and White: Racial Bias in the Decision to Shoot in a Multiethnic Context, $68 \mathrm{~J}$. OF SOC. Issues 286, 286 (2012).

${ }^{163}$ Implicit RaCial Bias ACross ThE LAW, supra note 120, at 19.

${ }^{164}$ See Alexander R. Green et al., Implicit Bias Among Physicians and Its Prediction of Thrombolysis Decisions for Black and White Patients, 22 J. GEN INTERNAL MED. 1231, 1231 (2007), available at https://www.ncbi.nlm.nih.gov/pmc/articles/PMC2219763//..

${ }^{165} \mathrm{Id}$.

${ }^{166} \mathrm{Id}$.
} 
(clot-busting) treatment to a white or black patient suffering from myocardial infarction. ${ }^{167}$ The more the doctors implicitly preferred white patients, the more likely they were to recommend thrombolysis to white, but not black patients. ${ }^{168}$ In another study, researchers designed a Guilty/Not Guilty IAT, which demonstrated that test participants strongly associated blackness with guilt as opposed to whiteness and "that the IAT scores predicted participants' evidence judgments." 169

\section{H. Implicit Bias Frames the Way We See Reasonableness and Becomes Its Central Repository.}

Implicit bias is the lens through which we engage the legal analysis of whether a police officer used excessive force reasonably in the face of a perceived danger. Under the Fourth Amendment, a police officer's use of physical force against an arrestee must be objectively reasonable under the circumstances. ${ }^{170}$ "The 'reasonableness' of a particular use of force must be judged from the perspective of a reasonable officer on the scene, rather than with the 20/20 vision of hindsight." "171 "[C]areful attention [must be paid] to the facts and circumstances of each particular case, including the severity of the crime at issue, whether the suspect poses an immediate threat to the safety of the officers or others, and whether he is actively resisting arrest or attempting to evade arrest by flight." 172 Consideration must be extended to law enforcement officials who are often forced to make split-second determinations in circumstances that are life threatening, tense, uncertain, and rapidly evolving. ${ }^{173}$ The use of deadly force is justified when "the officer has probable cause to believe that the suspect poses a threat of serious physical harm, either to the officer or to others...."174

\footnotetext{
${ }^{167} \mathrm{Id}$.

168 Id.

${ }^{169}$ Implicit Racial Bias Across The LAw, supra note 120, at 22-23.

${ }^{170}$ Graham v. Conner, 490 U.S. 386, 396-97 (1989). The deference to police officers' discretion is also replicated under Missouri law. Missouri Revised Statutes $\$ 563.046$ authorizes deadly force "in effecting an arrest or in preventing an escape from custody..." if the officer "reasonably believes . .$"$ it is necessary in order "to effect the arrest... and also reasonably believes that the person to be arrested ... [h] as committed or attempted to commit a felony; or ... [m] ay otherwise endanger life or inflict serious physical injury unless arrested without delay.” Mo. REV... STAT. $§ 563.046$ (2016).

171 Graham, 490 U.S. at 396.

${ }^{172} \mathrm{Id}$.

${ }^{173} I d$. at 396-97.

174 Tennessee v. Garner, 471 U.S. 1, 11 (1985); see also Nelson v. County of Wright, 162 F.3d 986, 990 (8th Cir. 1998); O'Bert ex. rel. Estate of O’Bert v. Vargo, 331 F.3d 29, 36 (2d Cir. 2003) (same as Garner); Deluna v. City of Rockford, 447 F.3d 1008, 1010 (7th Cir. 2006) (citing Scott v. Edinburg, 346 F.3d 752, 756 (7th Cir. 2003) (deadly force can be reasonably employed where an "officer believes that the suspect's actions place him, or others in the immediate vicinity, in imminent danger of death or serious bodily injury ...").. In Tennessee v. Garner, the Supreme Court held that an officer cannot arrest an unarmed felony suspect by shooting him dead. If the suspect threatens the officer with a weapon, or there is probable cause to believe he has committed a crime involving the infliction or threatened infliction of serious physical harm, deadly force may be used if necessary to
} 
The principle of reasonableness is a touchstone and linchpin of American Fourth Amendment jurisprudence. ${ }^{175}$ If Wilson reasonably believed his life was threatened, his use of force against Brown was legally justified, a case of justifiable homicide, which is precisely what resonated for the investigators, prosecutors, jurors, and many in the public. A police officer in Missouri can use deadly force in making an arrest or preventing escape if he reasonably believes it is necessary to effect the arrest and also reasonably believes the person to be arrested has committed or attempted to commit a felony, or may otherwise endanger life or inflict serious physical injury unless arrested without delay. ${ }^{176}$ In an effort to

prevent escape. An officer may use deadly force under certain circumstances even if the suspect is fleeing. "Where the officer has probable cause to believe that the suspect poses a threat of serious physical harm, either to the officer or to others, it is not constitutionally unreasonable to prevent escape by using deadly force. Thus, if the suspect threatens the officer with a weapon or there is probable cause to believe that he has committed a crime involving the infliction or threatened infliction of serious physical harm, deadly force may be used if necessary to prevent escape, and if, where feasible, some warning has been given." Garner, 471 U.S. at 11-12. An officer may not, on the other hand, use physical force, deadly or otherwise, once a threat has been neutralized. This is true even if the suspect threatened an officer's life - or that of another - prior to being brought under control. See Moore v. Indehar, 514 F.3d 756, 762 (8th Cir. 2008); see also Nelson, 162 F.3d at 990.

${ }^{175}$ [T] he ultimate touchstone of the Fourth Amendment is reasonableness. Brigham City, Utah v. Stuart, 547 U.S. 398 (2006).

${ }^{176}$ Fagan \& Harcourt: Missouri Revised Statutes $§ 563$ authorizes deadly force "in effecting an arrest or in preventing an escape from custody" if the officer "reasonably believes" it is necessary in order to "to effect the arrest and also reasonably believes that the person to be arrested has committed or attempted to commit a felony ...... or may otherwise endanger life or inflict serious physical injury unless arrested without delay." Mo. Rev. Stat. $\S 563.031 .1$ (2016), http://www.moga.mo.gov/mostatutes/stathtml/56300000311.HTML (Use of force in defense of persons. 563.031. 1. A person may, subject to the provisions of subsection 2 of this section, use physical force upon another person when and to the extent he or she reasonably believes such force to be necessary to defend himself or herself or a third person from what he or she reasonably believes to be the use or imminent use of unlawful force by such other person, unless: (1) The actor was the initial aggressor; except that in such case his or her use of force is nevertheless justifiable provided: (a) He or she has withdrawn from the encounter and effectively communicated such withdrawal to such other person but the latter persists in continuing the incident by the use or threatened use of unlawful force; or (b) He or she is a law enforcement officer and as such is an aggressor pursuant to section 563.046; or (c) The aggressor is justified under some other provision of this chapter or other provision of law(2) Under the circumstances as the actor reasonably believes them to be, the person whom he or she seeks to protect would not be justified in using such protective force; (3) The actor was attempting to commit, committing, or escaping after the commission of a forcible felony. 2. A person shall not use deadly force upon another person under the circumstances specified in subsection 1 of this section unless: (1) He or she reasonably believes that such deadly force is necessary to protect himself, or herself or her unborn child, or another against death, serious physical injury, or any forcible felony; (2) Such force is used against a person who unlawfully enters, remains after unlawfully entering, or attempts to unlawfully enter a dwelling, residence, or vehicle lawfully occupied by such person; or (3) Such force is used against a person who unlawfully enters, remains after unlawfully entering, or attempts to unlawfully enter private property that is owned or leased by an individual, or is occupied by an individual who has been given specific authority by the property owner to occupy the property, claiming a justification of using protective force under this section. 3 . A person does not have a duty to retreat: (1) From a dwelling, residence, or vehicle where the person 
demonstrate the reasonableness of his fear, Wilson characterized Brown as demonic, crazed, and beyond control, while Wilson characterized himself as vulnerable and fearing for his life, first in the police vehicle and moments later in the street after he ordered the fleeing, shot, and bleeding Brown to halt. "Officer Wilson then shot Brown repeatedly, according to his account, after Brown continued to charge at him" through four separate rounds of gunfire and Wilson's ordering Brown to get down on the ground. ${ }^{177}$

Wilson's claim that Brown stared into his pointed weapon and dared him to shoot, because he was too much of a "pussy," paradigmatically exemplifies racialized masculinity and sexuality on an intersectional implicit bias axis. Essentially, Wilson claimed that Brown reduced him to a vulnerable feminized orifice, ironically at the height of Wilson's power and potency, as his gun was drawn. Wilson's comment encapsulates the manner in which racial ideologies cleave gender norms, such that white men take on the traits of innocence, vulnerability, and susceptibility to violence and violation, when faced with black men who are perceived as dangerous, prone to violative behavior, in desperate need of being controlled, and a threat to white masculinity and consequently white heteropatriarchal order. Wilson's allegation typifies the manner in which black men are hypermasculinized and hypersexualized, in ways that make them vulnerable to police violence and justifiable homicide in order to maintain white heteropatriarchal order. ${ }^{178} \mathrm{It}$ is these very time-worn themes of racialized sexuality and masculinity that turned Wilson into victim and Brown into predator.

The reasonableness inquiry and implicit bias provide the perfect storm of framing black vilification and white innocence. In the grip of implicit bias, the black body itself becomes evidence of the crime and danger, and the white body becomes evidence of innocence and righteousness. The gaze or lens of valor melds with the white body and the gaze or lens of pathology never leaves the black body. The implicit bias research, particularly the shooter bias studies, demonstrates an endemic association between black people with dangerousness, regardless of whether they are actually armed. ${ }^{179}$ By way of illustration, and as Cynthia Lee suggests, the overwhelming majority of race based implicit bias test takers are

is not unlawfully entering or unlawfully remaining; (2) From private property that is owned or leased by such individual; or (3) If the person is in any other location such person has the right to be. 4 . The justification afforded by this section extends to the use of physical restraint as protective force provided that the actor takes all reasonable measures to terminate the restraint as soon as it is reasonable to do so. 5. The defendant shall have the burden of injecting the issue of justification under this section. If a defendant asserts that his or her use of force is described under subdivision (2) of subsection 2 of this section, the burden shall then be on the state to prove beyond a reasonable doubt that the defendant did not reasonably believe that the use of such force was necessary to defend against what he or she reasonably believed was the use or imminent use of unlawful force. (L. 1977 S.B. 60 , A.L. 1993 S.B. 180 , A.L. 2007 S.B. 62 \& 41, A.L. 2010 H.B. 1692, et al. merged with H.B. 2081, A.L.)).

${ }^{177}$ Bosman, supra note 61.

${ }^{178}$ See Harris, supra note 14 , at 16.

${ }^{179}$ Lee, supra note 140 , at $1584-85$. 
inclined to associate black people with danger, suspiciousness, and the need to be controlled and if the majority are more likely to "see" a weapon in the hands of unarmed Blacks than in the hands of comparable Whites and are therefore more likely to shoot unarmed Blacks when they would not shoot comparable Whites, then investigating officers, prosecutors, grand and petit jurors, judges, and the public at large may be more inclined to find that a white officer who shot an unarmed black person acted reasonably. ${ }^{180}$ Implicit bias research indicates that a white officer perceives danger in a black body, even when mistaken. ${ }^{181}$ This strong tendency to associate Blacks with danger provides another structural and cultural impediment to cases involving officer shootings of black people and the willingness of investigators, prosecutors, jurors, judges, and the public to excuse a police officer in the shooting death of an unarmed civilian. ${ }^{182}$

\section{Implicit Bias Frames the Way We See Evidence.}

Like other crimes involving societally vulnerable victims, such as sex trafficking, rape, or battered women's cases, implicit bias in police shootings inverts, if not perverts, the established criminal justice system, not just with respect to investigations and prosecutions, but also the relative value judgments made between victims and perpetrators. Implicit bias has the weight and power to reallocate the burdens of proof. As further evidence of the omnipresence of implicit bias, its entrenchment, and the internalization of dominant discourses, the fact finders in societally vulnerable victim cases render verdicts, true bills, and no bills that reflect the relative value between victims and the accused - the relative value, for example, of a white officer who protects and serves the societal order, or the life of a dead black man who dog whistle politics has framed as a demon. ${ }^{183}$ As another example, jurors in the Rodney King trial had a "reverence for the police officers as guardians of social order" and their "low regard for the likes of Kinga paroled felon, driving drunk and resisting arrest - made it inconceivable that they could sympathize with him as the victim of the alleged crime." 184 In sum, implicit bias frames the way we see the body of proof, the perception of racialized danger, the innocence of Whites, and the pathology of Blacks.

\footnotetext{
${ }^{180} \mathrm{Id}$.

${ }^{181}$ See id.

182 See, e.g., James Pinkerton, Bulletproof Part 3: Hard to Charge, Houston Chronicle, http://www.houstonchronicle.com/local/item/Bulletproof-Part-3-Hard-to-charge-24421.php (showing an example in Houston, Texas where local grand juries have cleared police of shooting civilians 288 consecutive times).

${ }^{183}$ Lawson, supra note 120 , at 365 .

184 Bob Sipchen, Analysis Backs Jury in Rodney King Trial, L.A. Times (Sept. 24, 1992), http://articles.latimes.com/1992-09-24/news/vw-1191_1_rodney-king-trial (quoting D.M. Osborne from the American Lawyer).
} 
The distinction between white heteropatriarchal space and vulnerable bodied places is not just an issue of perception; ${ }^{185}$ it creates two different material realities particularly with respect to white and black experiences with authority generally and the police specifically. ${ }^{186}$ It creates the circumstances under which police officers enter white neighborhoods and interact with its citizens as "officer friendly"; whereas, law enforcement engages battle tactics and guerrilla warfare in "bad" - used as a proxy for "black" - neighborhoods. This variance in perception and lived realities impacts jurors' perceptions of evidence in cases involving white officers killing unarmed black people. The majority white grand jury proceedings, like Wilson's where there were 9 white grand jurors, 6 men and 3 women, and 3 black, 1 man and 2 women, impact the perception of evidence, particularly the vilification of Blacks and the over valorization of Whites. ${ }^{187}$ Furthermore, an additional structural impediment to indicting white officers who kill unarmed black people exists because jurors often defer to the officer's credibility, giving the

${ }^{185}$ Borrowing from Yi-Fu Tuan's distinction between space and place, America itself becomes the racial battleground of white supremacy. See Yi-Fu Tuan, SPACE and Place: The Perspective of EXPERIENCE 5-7 (Univ. of Minn. Press 1977). In its basic operations, white heteropatriarchy usurps and totalizes all space and relegates specific bodies to places where the conditions of vulnerability to exploitation abound and ensnarl. Id. In a classic example, the Dred Scott decision denied citizenship to Blacks, leaving them without access to the courts or any form of justice and therefore vulnerable to exploitation for both purposes of labor and sex. Scott v. Sandford, 60 U.S. 393 (1856).

186 BENJAMIN B. RINGER \& ELINOR R. LAWLESS, RACE-ETHNICITY AND SOCIETY 21, 87, 88, 91, 9394, 95-97, 99, 100-01, 103, 104-05 (1989). These differing substratas with their attendant set of divergent norms and rules create divergent material realities and perceptions between Blacks and Whites. For example, in one poll involving the radically divergent racial perceptions of the Brown shooting, 23 percent of Whites believed that Brown was racially profiled, compared with 64 percent of Blacks. By contrast, 77 percent of Whites believed race did not factor into the shooting and 72 percent of Whites stated Wilson should not be arrested or charges. Seventy-one percent of Blacks, however, indicated that Wilson should have been arrested and charged with a crime. Jamelle Bouie, Tale of Two Fergusons, SLATE (Sept. 16, 2014, 5:47 PM), http://www.slate.com/articles/news_and_politics/politics/2014/09/st_louis_blacks_and_white_disag ree_on_michael_brown_s_killing_hold_almost.html.

In another poll, 39 percent of Whites believed that Blacks are "unfairly targeted by law enforcement," compared with 70 percent of Blacks. Moreover, 71 percent of Whites believed Saint Louis County Prosecutor Bob McCulloch was fair and impartial. Id.

${ }^{187}$ Derrick Clifton, There's Already a Serious Problem with the Michel Brown Trial, IDENTTTIES.MIC (Aug. 26, 2014), http://mic.com/articles/97232/there-s-already-a-serious-problem-with-the-michaelbrown-trial\#.9VacccDkJ. According to a Pew research Center study nearly twice as many Blacks as Whites believed that Wilson's case "raises an important issue about race," $80 \%$ to $44 \%$. Id. When asked about how fairly the Wilson's case would be evaluated only $18 \%$ of Blacks indicated confidence compared to $52 \%$ of Whites. Id. Power structures in suburbs that transitioned to majorityblack populations remain overwhelmingly white. Nickolas Kaplan, The Fire (This) Time: Ferguson, Implicit Bias, and the Michael Brown Grand Jury, 20 PUB. INT. L. REP. 52, 54 (2014). Ferguson, for instance, has a white mayor, a 6-white-1-Hispanic school board that recently suspended a black superintendent, one black City Council member, and a six percent black police force. Id. This is compounded by a municipal revenue scheme over-reliant on traffic citations by mostly white officers against black drivers: 86 percent of stops, 92 percent of searches, and 93 percent arrests in 2013 were of black drivers. Id. The grand jury thus replicates Ferguson's demographic power imbalance. Id. 
reasonableness of the use of force additional bite. Although there are jury instructions and voir dire practices to prevent jurors from over valuing the testimony of an officer, no such instruction was provided to the grand jury in the Wilson case.

\section{IMPLICIT BIAS IN THE WILSON GRAND JURY PROCEEDINGS}

The Wilson grand jury proceedings exemplify the inversion of order and the reallocation of the burden of proof when rules of evidence and legal definitions of "reason" are so laden with white heteropatriarchal assumptions about guilt, innocence, and danger. The prosecution torpedoed and jettisoned the state's ability to prove improper use of force, despite there being sufficient evidence to obtain a true bill, and despite the common wisdom that even a "ham sandwich" could be indicted by a vigorous prosecutor. Typically, again referencing the $99 \%$ success rates for prosecutors in obtaining true bills, the prosecution presents to the grand jury evidence establishing probable cause to believe that a target has committed a crime. By contrast, at trial, the prosecution puts on its case-in-chief, which is evidence establishing the defendant's guilt by a reasonable doubt standard of proof. In the Wilson grand jury proceedings, however, the prosecution inverted the process and presented the grand jurors with Wilson's case-in-chief. Arguably, the prosecution put on a defense of Wilson that was much better than any case-in chief Wilson's defense attorney could have presented at a trial. The prosecutors failed to guide the grand jury through the recommendation of charges; whereas at trial, the presiding trial judge would read the indictment to the petit jurors at the outset of the trial and then provide jury instructions to the jurors before they began their deliberations. Although the prosecution failed to provide a charging recommendation against Wilson, they provided a statute more favorable to his defense that was unconstitutional and enabled that statute to act as a filter for two months as the grand jurors heard evidence. In a trial, the erroneous statute would be subject to the adversarial process and challenge, where the prosecution (if it had a will to convict) could readily challenge the accuracy of the statute during a jury instruction conference and/or by way of motion. Moreover, had the case proceeded to trial, the evidence and particularly Wilson's testimony would have been subject to the Rules of Evidence and cross-examination. In the grand jury proceeding, the prosecution not only allowed Wilson to testify, but prosecutors gave him four hours to present his narrative, to frame the evidence around his narrative, and to be emancipated and liberated from the truth serum and elixir of cross-examination (challenge), which is particularly conspicuous when the prosecutors could have used the opportunity to create impeachment materials for trial against Wilson, and 
further contrasted markedly from the prosecution's rigorous cross-examination of its own witnesses. ${ }^{188}$

Though it might be tempting, then, to frame the issue solely through the lens of prosecutorial competence and discretion, such a framing implies that another prosecutor could do better. Yet the indictment and conviction rates of officers accused of excessive force indicates that other prosecutors do not do better. Here is where the analysis of implicit bias becomes central, for, it is in the prosecution of these cases that the "implicit" becomes "explicit" and material, embedded in the structure and practice of legal institutions beyond the particularities of who is at the helm. In the case of Wilson and Brown, three instances amply demonstrate this process of concretization.

First, it must be noted that Wilson benefited from the previously described anti-black, pro-police biases from the moment additional officers arrived at the scene of the shooting. Wilson's supervisor arrived at the scene; took Wilson's story, which was never documented; tried Wilson at the scene, determined his level of guilt, and let Wilson leave the scene with literal blood on his hands that he was allowed to wash off without being questioned or processed at the murder scene. ${ }^{189}$ Wilson's supervisor later explained that he sent Wilson home without being interviewed or processed because of the "hostile" crowd; ${ }^{190}$ but given that the crowd did nothing to indicate a threatening or violent intent, the supervisor's fear of the crowd may also indicate his own biases regarding black criminality and "dangerous neighborhoods." The result is that Brown was declared guilty and Wilson announced innocent at the murder scene itself, a fact that would hamper future prosecution.

In his post-incident interview and in his testimony to the grand jury, Wilson repeatedly referred to what he called "aggression" from Brown. He testified that he told the unarmed Brown to step back from his police vehicle three times, twice Brown responded by slamming the SUV door on Wilson and the third time, Brown assaulted him "swinging wildly," yet pausing briefly to hand a package to Dorian Johnson, his companion, and then continuing to punch the armed Wilson. ${ }^{191}$ Despite photographs revealing relatively minor redness and no visible scaring on the left side of his face, Wilson claimed that he had to pull his weapon, because Brown could have killed him with a single blow: "I felt that another one of those punches in my face could knock me out or worse. I mean it

188 See Offices of the United States Attorneys, U.S. Dep'T of Justice, U.S. ATtorneys' MANUAL § 9-11.152, (2012), available at https://www.justice.gov/usam/usam-9-11000-grandjury\#9-11.152 (states that "under normal circumstances, where no burden upon the grand jury or delay of its proceedings is involved, reasonable request by a 'subject' or 'target' or an investigation, as defined above, to testify personally before the grand jury ordinarily should be given favorable consideration ...."). Mr. Wilson was not rigorously cross-examined, while other witnesses were subject to extensive and aggressive cross-examination.

${ }^{189}$ Memorandum, supra note 11 , at 15.

${ }^{190} \mathrm{Id}$.

${ }^{191}$ Memorandum, supra note 11, at 13. 
was, he's obviously bigger than I was and stronger and the, I've already taken two to the face and I didn't think I would, the third one could be fatal if he hit me right." As yet another incident of the prosecution abandoning its cross-examining function, the prosecution failed to ask Wilson about the reasonableness of his perception of danger, when his claims about Brown punching him in the face to the point where he feared death did not square with the post-shooting photos of Wilson showing relatively minor, at best, injuries. ${ }^{192}$

Wilson stated he was carrying mace, a baton, and a flashlight; but he did not believe non-lethal force options would be effective. His gun, he said, was the only option. As Wilson pointed his gun at Brown and warned Brown that he would shoot, according to Wilson, Brown stared into his brandished and pointed weapon, refused to heed his warning, and stated: "You are too much of a pussy to shoot."193 According to Wilson, Brown's size and strength coupled with his standing outside the SUV made Wilson completely vulnerable despite Wilson's being armed and seated in an SUV. Again, according to Wilson, Brown responded to being shot the first time by becoming enraged, that Brown "looked like a demon," and Brown then put his head and arms back into the SUV and assaulted Wilson again. Wilson claimed that after he chased Brown, Brown turned around toward the armed Wilson appearing "psychotic," "hostile," and "crazy," as though he was "looking through" Wilson. Wilson claimed, after being shot at least once and after being chased by Wilson, Brown made a "grunting noise" and with what Wilson described as the "most intense aggressive face" that he had ever seen on a person, Brown then made a hop-like movement, and charged at Wilson. According to Wilson, while Brown reached for his waistband, which Wilson thought might be an attempt to retrieve a weapon, ${ }^{194}$ Wilson fired multiple shots and told Brown to get on the ground, to which Brown responded by briefly pausing and then charging at Wilson again with his hand in his waistband. According to Wilson, Brown charged at him three more times. Wilson fired a total of twelve shots. ${ }^{195}$

\footnotetext{
${ }^{192}$ See Goldwasser, supra note 26, at 54 n. 49. (pointing out, "Wilson's injuries consisted of scratches on his neck and relatively minor bruising and swelling of his right jaw, resulting in jaw pain, for which an anti-inflammatory and some ice were prescribed.")

${ }^{193}$ Memorandum, supra note 11 , at 13-14.

${ }^{194}$ Memorandum, supra note 11 , at 82 . A black man allegedly reaching for a gun is a perennial claim in many unarmed shooting cases.

${ }^{195} \mathrm{Id}$. at 16 . As further evidence of the manner in which pseudospeciation not only plays itself out in material reality, as exemplified in Brown's case, but also creates a reality, in August 2014, Fox News reporter Holly Mckay, reported that a "well placed source" confirmed that Wilson suffered a fractured eye socket from the scuffle with Brown. Hollie McKay, Missouri Cop Was Badly Beaten Before Shooting Michael Brown, Says Source, Fox News (Aug. 20, 2014), http://www.foxnews.com/us/2014/08/20/missouri-cop-was-badly-beaten-before-shooting-michaelbrown-says-source.html. Wilson himself claimed that he had been severely injured in the scuffle. The photos released of Wilson, during his medical exam immediately following the scuffle, however, at best showed some redness but no serious injury. Wilson and one other witness stated that Brown charged Wilson, again after the first shots. Sixteen other witness stated that Brown looked as if he was trying to surrender, and had his arms raised in the air when Wilson fatally shot him.
} 
When Wilson testified that Brown looked like Hulk Hogan, the prosecutors failed to challenge Wilson about his relative height, weight, and strength, ${ }^{196}$ providing added legitimation to Wilson's perception of Brown as demonic, aggressive, hostile, and crazy; this was an opportunity to bring the subconscious workings of implicit bias to light, and proclaim their impropriety as a basis for officers' use of force ${ }^{197}$ Further extending the wild, uncontrollable, animalistic image of Brown, Wilson testified that Brown just started hitting him through the window. The prosecutors failed to question the plausibility of a young black male hitting and assaulting an armed police officer in a police vehicle, let alone the photographs of Wilson after the incident that failed to reflect bruising from Hulk Hogan hitting him twice in the face. Similarly, the prosecution declined to question Wilson about Brown's pausing long enough during his assault of Wilson, armed and seated in an SUV, to hand Johnson the cigarillos. The prosecution chose not to challenge Wilson about his claim that Brown ran through bullets. They failed to probe how Wilson's testimony failed to align with the forensics, dispatch, and autopsy reports; instead, they allowed Wilson to construct his own narrative. The prosecution failed to have Wilson explain what he meant when he stated that Brown's community was not well liked, possibly leaving grand jurors to ponder whether Brown's neighborhood provided fodder for a probable cause determination to use force - whether Brown's neighborhood itself provided evidence of probable cause and dangerousness itself. Beyond the testimony itself, the prosecutors used Wilson's testimony as the fulcrum of the presentation, spending the next three months buttressing Wilson's testimony with witnesses that corroborated his story. ${ }^{198}$

Moreover, the Wilson grand jury proceeding illustrates the problematic nature of allowing the alleged character of a neighborhood to lead to an inference of a justified use of force. ${ }^{199}$ The proceedings demonstrate the legal creation of

196 Paul Rosenberg, Everything the Darren Wilson grand jury got wrong: The lies, errors and mistruths that let Michael Brown's killer off the hook, SALON (Nov. 26, 2014, 2:45 PM), http://www.salon.com/2014/11/26/everything_the_darren_wilson_grand_jury_got_wrong_the_lies and_mistruths_that_let_michael_browns_killer_off_the_hook/.

${ }_{197}$ See Memorandum, supra note 11 , at 14 .

${ }^{198}$ Bosman, supra note 61. Moreover, as Goldwasser illustrates, the prosecution directly contributed to Wilson's characterization of Brown as out of control, dangerous, suspicious, and in need of being controlled by presenting toxicology reports and witnesses about Brown's marijuana use and the subsequent possibility of hallucinations, paranoia, and psychosis that may have resulted from such use. Goldwasser, supra note 26 , at 48 . Goldwasser also points out that the prosecution asked several witnesses about the possibility that Brown had taken "wax," a highly potent form of marijuana, before the shooting although there was no basis for the questions in the record. Id. Two points bear repeating here: (1) the prosecution provided a better defense for Wilson in the grand jury proceedings than he ever would have received at trial and (2) as Anthony Farley argues lavishing Brown's body with narcotics use branded his body a site for social ills that justified the use of force. See Farley, supra note 2 , at 475 .

${ }^{199}$ Such inferences are not without legal precedent. In Illinois $v$. Wardlow, the Supreme Court held that an individual's presence in in an area of expected criminal activity, standing alone, was not 
vulnerability to excessive police force by (1) branding the neighborhood as "bad" and (2) allowing that branding to affect the reasonableness inquiry, and by extension reasonable suspicion and probable cause. Using Farley's insights, lavishing Brown's body and his neighborhood with drug use, danger, and suspiciousness branded both his body and surrounding area as a site for social ills that justified the use of force. This branding is particularly effective where the matrix of implicit bias advantaged Wilson over Brown, particularly with respect to presumed criminality and innocence. Marking Brown's neighborhood as an indicia of criminality not only reinforces implicit bias, it allows white heteropatriarchy to become the law, to do its work, and to subsidize its efforts.

What makes Wilson's story palpable and what makes his narrative resonate as "reasonable" is framing Brown as a demon and himself as innocent, vulnerable, and the only means of establishing order at the site of chaos. ${ }^{200}$ Wilson's narrative and frame, moreover, resonated for the investigators, prosecutors, grand jurors, and many common viewers of the American scene.

\section{POSSIBLE SOLUTIONS}

With implicit bias anchored in the very structure of the mind, the black body becomes synonymous with pathology and the white body instantaneously reflective of innocence. Implicit bias is itself evidence of crime, such that even where the black body is engaged in innocence, it is perceived as treacherous; where it exercises brilliance, it is measured as mediocre; and where it is valiant, it is framed as diabolical. By contrast, the white body becomes synonymous with righteousness. It is itself evidence of innocence, such that where it engages in

enough to support a reasonable, particularize suspicion that the person is committing a crime. Illinois v. Wardlow, 528 U.S. 119, $119(2000)$. But officers are not required to ignore the relevant characteristics of a location in determining whether the circumstances are sufficiently suspicious to warrant further investigation. Id. Accordingly, we have previously noted the fact that the stop occurred in a "high crime area" among the relevant contextual considerations in a Terry analysis. See id. at 119-20. Similarly, in Whren, the Court noted that the defendant was in a "high drug area," in fashioning its bulwark against inquiries into pretextuality and subjective motivations for stopping citizens where they have also committed traffic violations. Whren v. United States, 517 U.S. 806, 808 (1996). Ostensibly, "high drug areas, areas of suspected criminal activity, and bad neighborhoods would not include places where doctors may be overprescribing opioids or illegally providing them without a prescription.

${ }^{200}$ It should be noted that "being threatened" is the domain of white heteropatriarchy and does not extend to Marrisa Alexander, a battered black wife, who fired a warning shot at her abusive husband (to make him get out of the house), and whose Stand Your Ground motion was denied. See Stephen A. Crockett, Jr., Marissa Alexander Released from Prison, THE RoOT (Jan. 28, 2015), http://www.theroot.com/articles/news/2015/01/marissa_alexander_released_from_prison/).

Similarly, Trayvon Martin was not entitled to public space nor was he allowed to be a child being stalked by Zimmerman, assuming honorary whiteness. White heteropatriarchy usurps and totalizes the field of victimhood and relegates black bodies to places of perpetrators, where their suffering and victimization is rendered invisible. 
treachery, it is perceived as innocent; where it exercises mediocrity, it is measured as brilliant; and where it is diabolical, it is justified as valiant. This dichotomy forms the pathological gaze and the gaze of over-valorization, which dictate that the black body is always seen as embodying pathology and the white body is always viewed as righteous regardless of the proof and irrespective of the context. Black demonry and white innocence are not only the lens through which we see evidence, they become the evidence itself, existing long before the actual proof. Once declared the site of menace (which occurs upon first sighting), the black body, like the black neighborhood, becomes vulnerable to the performance of white heteropatriarchy, the unleashing of anxiety on the canvass of black flesh in order to mangle, but more importantly to declare shared triumph, vindication, safety, and security. White heteropatriarchy usurps the function of the law in order to hide, obfuscate, and exact its agenda, which is the control, subjugation, and domination of the black body, legitimated through operations of law, like the grand jury proceeding in the Wilson case. Within the law, white heteropatriarchy is highly adaptable. It grafts onto the law, creating its own imperceptibility and relentlessly transformative nature, rendering its operations innocent, hidden, undetectable, and seemingly natural. ${ }^{201}$

Any solutions to the problem of white heteropatriarchal omnipresence, entrenchment, and inevitability must be as equally robust and comprehensive as the problem of white heteropatriarchy itself. Ferguson and the democratization of public discourse made possible through revolutionary increases in technology ignited a firestorm of "national dialogue on systemic racism in policing, the justice system, media discourse...social institutions" and cultural representations. ${ }^{202}$ Implicit bias research instructs that the reasonableness inquiry for excessive use of police force cases is a centralized repository and haven for racialized bias, inviting frameworks that establish criminality based on blackness and innocence hinging on whiteness. As a direct result, and as Cynthia Lee argues, the only way to disrupt the problems of implicit bias is to make race salient, as opposed to deluding ourselves into thinking that we have achieved post-racialism, which like

${ }^{201}$ Some critiques more sympathetic to the absence of a true bill in the Wilson proceedings have argued that legal scholars who criticize the Wilson adjudication have not advanced the evidence that would have established Wilson's guilt by a probable cause standard, let alone a reasonable doubt standard. In response to that observation, however, we unfortunately do not know what the prosecution's case in chief would look like against Wilson because the prosecution elected to present a better case in chief for Wilson than he would have otherwise received had the case proceeded to trial. For example, we have yet to see what the charging recommendations would have been (had there been a will to prosecute), what impact unsullied witnesses would have made, what demeanor evidence would have been produced had Wilson been rigorously cross examined, or what contradictory statements Wilson would have made had he been challenged. Furthermore, during the course of the proceedings, the prosecution produced impactful amounts of Brady and Giglio materials that would severely undermine the prosecutions witnesses had the case proceeded to trial. In short, there is an argument that we simply do not know what the evidence would have been had there been an unfettered will to prosecute.

202 Kaplan, supra note 187 , at 56. 
colorblindness silences any remedial effort and places white heteropatriarchy far beyond remedial reach. ${ }^{203}$ In that vein, omnipresent, ubiquitous, full, open, candid, inexhaustible, and complete vetting of white heteropatriarchy is mandated in order to arrest its effects and to make its operations known and knowable for purposes of correction. ${ }^{204} \mathrm{~A}$ thorough investigation, indictment, conviction, and sentencing of white heteropatriarchy are centuries long overdue.

A sustained and comprehensive national conversation, such as that being pushed by organizations affiliated with Black Lives Matter, may lead to the political mobilization that eventually mitigated the societal practice of lynchings. ${ }^{205}$ A legal strategy, if there is one, is not enough. Sustained dialogue and activism vetting the omnipresent, entrenched operations of white heteropatriarchy elicits the ears of prosecutors, ${ }^{206}$ judges, policy makers, and legislative actors, in addition to incentivizing political action. Political discourse makes carceral policy. Willie Horton and black demagoguery built a political consensus that led to action. So too, a sustained and highly public discourse about the operations of white heteropatriarchy has the potential to enlighten and change both the public and legal discourse. Judges listen. Police unions listen. Prosecutors listen. At a bare minimum, police unions now know to tell their affiliates to coordinate their stories with the available body and dashboard camera videos before they provide statements, particularly documented interviews. Such attentiveness might also lead to more proactive measures to eliminate the problems of implicit bias throughout the ranks. White heteropatriarchy cannot be talked about, theorized, problematized, nor discussed enough. ${ }^{207}$

${ }^{203}$ Lee, supra note 140 , at 1609-10.

${ }^{204}$ If Michel Foucault is correct in that "power is tolerable only on condition that it mask a substantial part of itself" and "[i]ts success is proportional to its ability to hide its own mechanisms[,]" then unmasking, unraveling, revealing, and deconstructing power is mandatory in order to render it intolerable and woefully unsuccessful. Michel Foucault, THE History of SeXUality, Vol. 1: AN INTRODUCTION 86 (1976).

${ }^{205}$ Michael J. Klarman, The Racial Origins of Modern Criminal Procedure, 99 MiCH. L. REV. 48, 60 (2000).

206 See, e.g., Leon Neyfakh, Big Wins for Black Lives Matter, SLATE (March 16, 2016), http://www.slate.com/articles/news_and_politics/crime/2016/03/the_prosecutors_in_the tamir_rice and laquan_mcdonald_cases_lose_their_primary.html. As a direct result of effective poititical organizing, the Black Lives Matters Movement has successfully mobilized voters and prompted the overthrow of two key prosecutors: Cook County state's attorney Anita Alvarez, who waited 13 months to bring charges against the Chicago police officer who shot Laquan McDonald, unarmed black youth, 16 times and Cuyahoga County district attorney Tim McGinty, who oversaw the grand jury proceedings that led to a no true bill against the officers responsible for the homicide of 12-yearold Tamir Rice. Id.

${ }^{207}$ Far from criticizing the media as the source of the problem for the national uprisings protesting excessive use of police force, the increased media coverage of these events has galvanized increased political discourse and activism that has successfully led to the ouster of two life-long prosecutors in Cook County, Illinois, and Cleveland, Ohio, the Laquan McDonald and Tamir Rice cases respectively, raising a political reckoning that led to successful public office removal. Exhaustive media coverage allows sunlight to act as natures greatest antiseptic in excessive use of force cases 
In order to circumvent the work of white heteropatriarchy in the criminal justice system, particularly in the area of police shootings, I suggest several solutions, three of which I discuss in some detail. However, in addition to these three, I also endorse mandatory implicit bias training throughout the ranks of law enforcement to include local law enforcement, federal agents, and state and federal prosecutors. Training should, at a minimum, make law enforcement much more critically aware of the operations of race, as well as class and gender, in their decision-making and exercise of authority. Implicit bias training should be mandatory at the National Advocacy Center, the national training facility for the nation's federal prosecutors, the highest form of law enforcement in whom the well-being of the nation is entrusted. Making law enforcement critically aware of and most importantly accountable for its implicit bias is imperative in order to ameliorate its effects.

I realize that many argue that making officers aware of racism in the exercise of police power or increased surveillance of officers increases crime because officers are inhibited from doing their jobs. These arguments, however, are prima facie problematic. In fact, these statements embody the very nature of the problem itself, an unbridled claim of white heteropatriarchal privilege and entitlement to perform on the canvasses of black flesh. It cannot be that officers need a fair margin of error, to include unarmed shootings of blacks, in order to do their jobs or that increased scrutiny inhibits officers' willingness to engage crime. It cannot be that officers need 20 unarmed black killings for every one million successful arrests or that we remove "public" from service in order to give officers the apparent secrecy and clandestine arrangements they need to police "bad" black areas, whose very nomenclature may appear redundant to them. The claim that these unarmed shootings are a necessary evil when policing black pathology is problematic at a bare minimum. The sheer number of murders of black persons by white officers and the lack of convictions for these instances of violence makes the case for greater diversity throughout the ranks of law enforcement and the criminal justice system to include police officers, state troopers, federal agents, prosecutors, judges, and jurors. I realize, however, that white heteropatriarchy uses "unqualified" and "unacceptable" as proxies for racism, making greater employment diversity a thing hoped for, but yet unseen, particularly through the lens of implicit bias.

I also endorse body and dashboard cameras, which will lend credibility to the claims of the vulnerable, pathologized, and framed as lacking in believability. The same white supremacy, white heteropatriarchy, and implicit and explicit bias that kills black bodies also refuses to believe black bodies. Although not dispositive, as in the case of Eric Garner, video provides another body of proof and subjects excessive use of force to the natural antiseptic of sunlight. Brown's death was not captured on a body or dashboard camera, but had it been, it may have

and it better positions citizens to seize the political process in order to make prosecutors accountable for their decisions, actions, measures of stealth, and good and bad faith. 
protected the integrity and credibility of both killer and victim. Like other evidence retention policies, the retention of these videos can be negotiated and balanced against the needs of law enforcement for storage space, like all forms of evidence retention.

In order to overcome the structural conflict of interest in having law enforcement investigate and prosecute law enforcement, there should be special investigators and prosecutors with increased scrutiny by the DOJ Civil Rights Division in all cases involving excessive use of force. The special prosecutors and investigators should comprise distinct departments and divisions with clear chains of command separate and apart from the targets of their investigations and prosecutions. Some scholars, activists, and commentators have argued that excessive use of force cases should, of necessity, be presented in a preliminary hearing before a judge under public scrutiny, rather than a secretive and clandestine grand jury operation. This partial solution necessitates some debate; however, it is not the mechanism of the grand jury, per se, that is the problem, but rather the will and desire of the prosecutor. ${ }^{208}$ As I have argued throughout this piece, grand juries are significantly structured to the distinct advantage of the prosecution, which is a well desired boon in difficult prosecutions when there is a will to convict ultimately. Just as the grand jury process can be manipulated to undermine a prosecution, it can also be used to bulwark an adjudication. Prosecutors can use the secrecy of a grand jury to protect the identity of witnesses, their credibility, as well as their stories. For example, in grand jury proceedings, prosecutors can prepare statements for their witnesses to read subject to their review for complete veracity, which enables the witness to produce consistent narratives under oath that can later be used at trial, particularly where the consistency of their claims are under siege. A preliminary hearing, on the other hand, subjects witnesses to often rigorous cross-examination, particularly at the risk of creating Brady and Giglio materials. Moreover, the prosecutorial discretion afforded prosecutors in grand juries allows them to laser focus the evidence necessary to establish probable cause liberated from the Rules of Evidence, Brady, Giglio, and suppression problems. In short, grand juries provide a well-suited vehicle for prosecution, again, where there is a desire to obtain charges and convictions. ${ }^{209}$ These structural advantages should not be lightly abandoned in excessive use of force cases; however, special prosecutors and investigators with greater DOJ oversight might eliminate the

\footnotetext{
${ }^{208}$ It should also be noted that in federal criminal proceedings, the Fifth Amendment mandates that felony charges be brought by grand jury indictment. U.S. CONST. amend. V; see also Hurtado v. California, 110 U.S. 516, 538 (1884).

${ }^{209}$ Goldwasser, supra note 26 , at 50 (explaining the prosecutorial will, or lack thereof in the Wilson proceeding, Goldwasser suggests that McCulloch deliberately used the grand jury, as opposed to a preliminary hearing or the filing of information, because it would ensure secrecy; unmitigated prosecutorial discretion; discretionary cross examination, allowing Wilson to provide his narrative without challenge and framed by favorable evidence and law; and perhaps most importantly, political cover because the citizens, in the form of the grand jurors, would be responsible for the absence of a true bill).
} 
inherent conflict of interest of law enforcement investigating and prosecuting its own, as well as ensuring, perhaps, a greater will to pursue convictions zealously. The idea, therefore, is not to cavalierly abandon the grand jury process, but to demand greater accountability and higher standards of fairness. Special prosecutors as well as investigators with enhanced DOJ oversight would at a bare minimum ameliorate the structural conflicts of interest when law enforcement investigate and prosecute their own. ${ }^{210}$

In addition to the aforementioned solutions, I also suggest as curatives the following:

\section{A. Local Police Department Reporting Requirements to Federal Agencies}

Disrupting the societal problem of police shooting unarmed persons mandates a legally mandated national database accessible to the public. In order to make known and knowable the full extent of the problem, a federal agency, like the Federal Bureau of Investigations (FBI) or the DOJ should gather legally mandated data to record the number of police shootings - fatal and nonfatal-per year, as well the race and gender demographics of both the victim and the perpetrator. ${ }^{211}$

${ }^{210}$ As an ancillary matter beyond the purview of the instant article, the prosecutorial treatment that Darren Wilson received - the arguable affirmative action - stands as a paradigmatic corrective and remedy to wrongful convictions and mass incarceration. If every defendant received what Wilson received during the course of his investigation and prosecution, the numbers of wrongful convictions and convictions generally would greatly dwindle. If defendants are allowed to leave the scene of the crime without being processed; if defendants are provided attorneys from the very outset of the investigation; if defendants can be shielded from making any statements at the scene of the crime or outside the presence of an attorney concretely and far beyond Miranda; if the defendants receive all of the evidence, not merely the discovery, within days of the incident; if defendants are allowed to testify in the grand jury free of any challenge and the Rules of Evidence, as well as having the added benefit of being able to coordinate their story with all of the evidence before providing testimony; if their narratives are framed by supporting witnesses before they begin to testify; if corroborating evidence and exculpatory materials are used to corroborate their claims during and after they testify; if the prosecutors endeavor to create and permit narratives that resonate for the grand jurors at the deepest layers of their conscious and subconscious minds; if the prosecutors refrain from providing charging recommendations; if the prosecutors provide the legal defenses for the defendants at the outset of the grand jury proceedings, particularly without the possible charges that defendant may have committed; if the prosecutors submit the grand jurors to a deluge of all the evidence without guidance or direction as to possible charges at the outset; such practices would greatly diminish overcriminalization, particularly of the truly innocent.

${ }^{211}$ See Wesley Lowery, How many police shootings a year? No one knows, WASH. PosT (Sept. 8, 2014), https:/www.washingtonpost.com/news/post-nation/wp/2014/09/08/how-many-policeshootings-a-year-no-one-knows/ (quoting D. Brian Burghart, editor and publisher of Reno News \& Review and creator of the Fatal Encounters project, as saying: "One of the government's major jobs is to protect us. How can it protect us if it doesn't know what the best practices are? If it doesn't know if one local department is killing people at a higher rate than others? When it can't make decisions based on real numbers to come up with best practices?"). 
[W] hile the federal government and national research groups keep data and statistics- on topics ranging from how many people were victims of unprovoked shark attacks (53 in 2013) to the number of hogs and pigs living on farms in the United States (upwards of $64,000,000$ according to 2010 numbers) - there is no reliable national data on how many people are shot by police officers each year. ${ }^{212}$

The DOJ does not maintain a "comprehensive database or record of police shootings, instead allowing the nation's more than 17,000 law enforcement agencies to self-report officer-involved shootings as part of the FBI's annual data on 'justifiable homicides' by law enforcement."213 DOJ, however, stopped releasing these numbers because they were deemed unreliable. ${ }^{214}$ Moreover, least we engage the trick of post-racialism and believe that race is just an idea to be overcome by being ignored; this legally mandated record gathering should be further delineated by, among other things, race as well as gender. White heteropatriarchal performance in racialized police violence, investigations, and adjudications is equally applicable to both black men and women; however, thoroughly delineated data would present an opportunity to analyze the distinctiveness of black men's and women's experiences with police violence"uniquely informed by race, gender, gender identity, and sexual orientation ... "215

According to the executive director of the Police Executive Research Forum, a comprehensive database of police shootings would enable law enforcement to analyze when police force is authorized; thereby, potentially leading to policy changes that might ameliorate unnecessary and unjustifiable use of force. ${ }^{216}$ An accurate record of police shootings would provide a complete and comprehensive study of police use of lethal force nationally. This assessment would create a baseline number or rate, from which states and the federal government might devise legislation to address excessive use of force. Furthermore, this publically accessible information may place pressure on law enforcement to adopt new policies that ameliorate the number of unarmed police shootings and incentivize them to exercise better discretion. However, we cannot stop there. The new laws and policies adopted must progressively seek to diminish

215 See Kimberle' W. Crenshaw \& Andrea J. Ritchie, African Am. Policy forum, Say Her Name: Resisting Police Brutality Against Black Women 3 (2015), available at http://static l.squarespace.com/static/53f20d90e4b0b80451158d8c/t555a810d7e4b058f342f55873/1 437077719984/AAPF_SMN_Brief_full_singles.compressed.pdf.

${ }^{216}$ Lowery, supra note 211. 
the practice of over-policing, over-surveilling, and over-incarcerating bodies of color.

\section{B. National Database of Local and Federal Prosecutions of Police Shootings}

Disaggregated data is needed at local, state, and federal levels by sex, race, reason for police interaction, assault, or death. The data should reflect the intersectionality of the police interactions and shootings. Along the lines of reporting requirements for police departments, the absence of indictments and convictions in cases involving police shooting unarmed persons requires a legally mandated national database accessible to the public that catalogues indictments and conviction rates of law enforcement shootings. As sunshine may be the one of the greatest antiseptics and in order to make known and knowable the full extent of the problem involving juror reluctance to indict and convict law enforcement who shoot the unarmed, as well as prosecutors who are loathed to seek indictments and solid convictions, a federal agency should gather legally mandated data to record the number of indictments, no true bills, convictions, and acquittals of police shootings - fatal and nonfatal-per year, as well as the race and gender demographics of both the victim and the perpetrator. A comprehensive database of adjudications would enable prosecutors and policy makers to analyze both the grand jury and trial process where police are defendants accused in a shooting; thereby, potentially leading to policy changes that might address the sometimes questionable use of grand juries to vindicate law enforcement and the trial dynamics that may lead to acquittals. ${ }^{217}$ An accurate record of indictments and convictions would provide a complete and comprehensive study of grand jury and trial processes nationally. This assessment would create a baseline number or rate, from which state and federal might devise corrective policy measures as well as the remedial grand jury process and trial strategies surrounding excessive use of force cases, i.e., voir dire questions that screen for implicit bias. Furthermore, this publically accessible information may place pressure on prosecutor offices to adopt new policies that ameliorate the questionable number of no true bills and possible convictions and incentivize them to exercise better diligence and even perhaps, diversity in their hiring. ${ }^{218}$

\footnotetext{
${ }^{217}$ See id.

218 "Sixty-six percent of states that elect prosecutors have no blacks in those offices....About 95 percent of the 2,437 elected state and local prosecutors across the country in 2014 were white . . . The study also found that 16 percent of elected prosecutors were white women, 4 percent were minority men and 1 percent were minority women .... 'What this shows us is that, in the context of a growing crisis that we all recognize in criminal justice in this country, we have a system where incredible power and discretion is concentrated in the hands of one demographic group,' said Brenda Choresi Carter of the Women Donors Network, who led the study." Nicholas Fandos, A Study Documents the Paucity of Black Elected Prosecutors: Zero in Most States, N.Y. TimEs (July 7, 2105), http://www.nytimes.com/2015/07/07/us/a-study-documents-the-paucity-of-black-electedprosecutors-zero-in-most-states.html?_r=0Id.
} 
The absence of data gathering arguably allows the problems of police violence to persist. The absence of record keeping provides additional protection from both the scrutiny and detection that might motivate corrective action. Conversely, the use of record keeping might incentivize correction, particularly where it might prompt public shaming, whereby law enforcement is subjected to the shame of their numbers and data. This publically accessible information would also enable the electorate to hold its public officials accountable, much like the events that saw the toppling of prosecutors in Cook County Illinois and Cleveland, Ohio after the LaQuan McDonald and Tamir Rice cases respectively. The data would provide a context in which to place these cases and would allow for the drawing of analogies and symmetries between excessive use of force cases with greater accuracy that can potentially lead to better policy. As an added benefit, data can bring these cases into high relief, giving them the high profile that necessitates greater transparency, answering the questions what do prosecutors do and how do grand juries operate, all of which enhances the democratic accountability of prosecutors in particular, but may have a subsequent trickling effect throughout the ranks of law enforcement.

Like CompStat, which focuses on using dynamic data of criminal activity in specific areas to target resources, triage, and increase oversight, massive data gathering would allow policy makers and the public to scrutinize those counties and/or police departments that manage to avoid high numbers of excessive force cases as well as those that appear particularly problematic and to ask what appears to be working and what is flawed. The same logic and justifications for CompStat would also apply to prosecutors' offices and their handling of these cases.

This data gathering might substantiate the hidden assumptions that "Black Lives Matter" challenge, particularly that blackness is not life and that black life does not matter as evidenced in the disproportionate number of blacks killed by white officers as well as the converse, the absence of disproportionate whites killed by black officers, particularly white women murdered by black male officers. Such evidence might also substantiate the claim that "White Lives Matter," further undermining the claim that "All Lives Matter." Even for those that are skeptical about the influence of race, white supremacy, or white heteropatriarchy in the instances of police encounters, data gathering might be an initial remedy. Such data might lead to systemic changes in policing that impact everyone. There is a clear argument that the number of police shootings generally is far too high to be cognized and that systemic changes are necessary to remediate the large numbers of police shootings and instances of excessive use of force across the board. In keeping with Derrick Bell's interest convergence, ${ }^{219}$ the data can be used to

${ }^{219}$ Derrick Bell's interest convergence theory posits that any corrective action benefits to blacks are incidental to, and contingent upon, benefits that whites receive; blacks will only receive corrective remedy when white interests are implicated and assuaged; that corrective action often masks the implicit norm of whiteness and white privilege, which allows the subtle reification of white supremacy and white heteropatriarchy by producing the same racial norms and codes of behavior 
demonstrate that systemic change in police culture, norms, and conduct is necessary for the betterment of the collective.

\section{Legislative Changes to Laws Involving a Disparate Racial Impact in Criminal Justice}

The full scope of legislation necessary to disrupt the racial impact of the criminal justice system on persons of color is far beyond the humble trajectory of this piece. ${ }^{220}$ "Over-criminalization, over-punishment, and discriminatory policing and prosecution define the [biased and broken] contemporary criminal justice system. ${ }^{221}$ This affects daily policing activities, such as who police deem suspicious and subject to Terry stops ....".222 "Law enforcement fits into a starkly racialized justice system that disadvantages and targets people of color. ${ }^{223}$ Just after 1980 , racial disparities increased dramatically in everything from arrests to incarceration, largely due to the 'War on Drugs' initiated by the conservative Bush, and Reagan administrations. ${ }^{224}$ Overall, from 1980 to 2008 , the number of incarcerated persons quadrupled from 500,000 to 2.3 million, ${ }^{225}$ with the United

that led to the corrective action in the first place; and finally that corrective action, like Brown $v$. Board of Education, often does the work of white supremacy and white heteropatriarchy because the legal process, the legal decision-making in the case of Brown, inoculates implicit norms embedded in the remedial action from detection. Derrick Bell, The Interest-Convergence Dilemma and Brown v. Board of Education, 93 HARV. L. REv. 518, 528-533 (1980). I use interest convergence theory to make the case for data gathering that would benefit everyone with the added benefit of casting into stark relief the intersectional demographic information surrounding police use of force cases as well as the adjudications that surround them for purposes of both detection and remedy.

${ }^{220}$ See generally Zach Newman, "Hands Up, Don't Shoot": Policing, Fatal Force, and Equal Protection in the Age of Colorblindness, 43 HASTINGS ConST. L.Q. 117, 153 (2015). The Sentencing Project, along with other scholarly and advocacy projects, however, have made the case for comprehensive policy and legal changes to reduce racial disparities and the use of fatal force in policing. Nazgol Ghandnoosh, The Sentencing Project, Black Lives Matter: Eliminating RACIAL INEQUITY IN THE CRIMINAL JUSTICE SYSTEM 19-20 (2015), available at http://sentencingproject.org/doc/publications/rd_Black_Lives_Matter.pdf.

${ }^{221}$ Newman, supra note 220, at 134.

${ }^{222} I d$.

${ }^{223}$ Id at 135; see also Aliya Saperstein et al., The Criminal Justice System and the Racialization of Perceptions, 651 ANNALS AM. ACAD. POL. \& Soc. SCI. 104, 106 (2014) ("As it currently operates, the criminal justice system differentially targets and differentially punishes black Americans, in particular, with similarly disparate consequences for their families and communities.").

${ }^{224}$ Newman, supra note 220, at 135; see also Michael Tonry, Racial Politics, Racial Disparities, and the War on Crime, 40 Crime \& Delinquency 475, 475 (1994).

${ }^{225}$ Newman, supra note 220, at 135 . "At the turn of the century, one percent of the U.S. population was in jail or prison and three percent were on parole or probation. Between 1982 and 1999, drug sentences in federal and state prisons increased by 975 percent. Two-thirds of people of color in prison are there for drug offenses. Black Americans are incarcerated at almost six times the rate of white Americans. More than sixty percent of people in prison are people of color, and one in ten black men in their thirties is in prison or jail on any day. One in three black boys will spend at least some of their lives in jail or prison, and one out of three black males is under the criminal justice 
States now incarcerating twenty-five percent of the world's prisoners ..." and making America the most carceral nation in history. ${ }^{226}$ America's rates of incarceration are so high that consensus exists between both Democrats and Republicans that reform is mandatory. ${ }^{227}$

Post-racialism, colorblindness, implicit bias anchored presumptions of white innocence and black demonry, legal formalism that erases historical contextuality and socio-economic material reality, and Equal Protection Clause jurisprudence "intersect to support the constitutional requirement of intent." 228 According to the Supreme Court in McCleskey v. Kemp, even if a neutral law has a disproportionately adverse effect upon a racial minority, it is unconstitutional under the Equal Protection Clause only if that impact can be traced to a discriminatory purpose. ${ }^{229}$ Thus, "a plaintiff must have a 'smoking gun' of discriminatory intent . . .".230 Where "a policy or law has a disproportionate and disparate impact, it only matters whether that policy or law was designed with the intent and purpose to discriminate."231 The insistence on direct proof of discriminatory impact is at odds with implicit bias, as well as its ubiquity. Implicit bias is the silent conspiracy in the room, whose power is so manifest it need not be spoken and it is unquestionably shared.

As a partial corrective and immediate response to the impact of race on the criminal justice system, legislators should proactively analyze racial impact statements, which offer one method of measuring the projected impact that new criminal justice laws and policies may have upon persons of color. In keeping with

system's control, such as on parole. In 2014, more black men were incarcerated and on probation or parole than were enslaved in 1850. In addition, one third of people disenfranchised because of felony convictions are black, which means that eight percent of all adult black Americans are disenfranchised. Black adults are four times more likely to lose their voting rights than all other adults. In Alabama, Kentucky, and Florida, one out of every five adult black Americans is unable to vote." Id. at 135-36. This is due to racial violence facilitated by a "system that purports to be neutral, post-racial, and 'colorblind,' based on the idea of increased formal access to civil rights for formerly excluded populations." Id. at 138.

226 Newman, supra note 220, at 135; see also Criminal Justice Fact Sheet, NAACP, http://www.naacp.org/pages/criminal-justice-fact-sheet (last visited Nov., 22, 2016).

${ }^{227}$ Ta-Nehisi Coates, The Black Family in the Age of Mass Incarceration, THE ATLANTIC, Oct. 2015, available at http://www.theatlantic.com/magazine/archive/2015/10/the-black-family-in-the-age-ofmass-incarceration/403246/.

${ }^{228}$ Newman, supra note 220, at 139.

${ }^{229}$ McCleskey v. Kemp, 481 U.S. 279, 298 (1987) (stating, "But “"[d] iscriminatory purpose" . . ... implies more than intent as volition or intent as awareness of consequences. It implies that the decisionmaker, in this case a state legislature, selected or reaffirmed a particular course of action at least in part "because of," not merely "in spite of," its adverse effects upon an identifiable group." (quoting Pers. Adm'r of Massachusetts v. Feeney, 442 U.S. 256, 279 (1979))).

${ }^{230}$ Newman, supra note 220, at 140.

${ }^{231} I d$. at 141 . 
making race salient as a corrective to white supremacy, this information is vitally important to legislators before they decide whether to enact a law. ${ }^{232}$

\section{Using Implicit Bias Research to Screen Law Enforcement Candidates as Part of the Application Process}

Implicit bias research and cognitive testing might be used to screen applicants in law enforcement. As the shooter bias studies demonstrate, implicit bias is not just an idea. It is a cognitive imperative that leads to action, from microaggressions to macroaggressions: people get shot. Research demonstrates that shoot/don't-shoot training can reduce implicit shooter bias. ${ }^{233}$ Law enforcement officers in this study participated in a shooter simulation similar to the one used by Correll. ${ }^{234}$ Although they mistakenly shot unarmed black suspects more than unarmed white suspects at first, the racial bias was completely eliminated after extensive practice with the program. ${ }^{235}$ In another study, "researchers concluded that while these officers exhibited bias in their speed to shoot, their experience and training reduced bias in their decision to shoot." ${ }^{.236}$ Possible explanations for the outcomes may be that when implicit bias is made known, knowable, and salient, officers place greater attention on their explicit, biased attitudes, thus overcoming the subconscious bias. Part of the privilege of white heteropatriarchy is its invisible nature and its inherent claims of innocence that inoculate it from detection, punishment, sanction, and correction. When white heteropatriarchy is unmasked and laid bare, particularly through public shaming, it is forced to reckon with itself. Like the video images of southern white police officers water hosing civil rights protestors or the numerous films depicting Nazi atrocities during the Holocaust, public shaming or bringing atrocities to the forefront may incentivize correction. It may also provide another impetus to hide and morph its operations. Nevertheless, research demonstrates that trainings can reverse or mitigate the results. Extended further, this research should be used to explore the possibility of screening devices as part of the application process for law enforcement. Authorizing officers to use lethal force and arming them with the means to do it, knowing that implicit bias research dictates that black bodies are more likely to be shot than armed white bodies is irresponsible. Given the empirical research on implicit bias, the continued authorization of law enforcement to police bodies of colors, particularly with guns, without controlling for implicit bias, is problematic at best. At least twenty-five percent of the population, if in fact

${ }^{232}$ See Jessica Erickson, Racial Impact Statements: Considering the Consequences of Racial Disproportionalities in the Criminal Justice System, 89 WASH. L. REv. 1425, 1425 (2014).

${ }^{233}$ See E. Ashby Plant \& B. Michelle Peruche, The Consequences of Race for Police Officers' Responses to Criminal Suspects, 16 PsYCHOL. SCI. 180, 183 (2005).

${ }^{234} \mathrm{Id}$. at 180.

${ }^{235} \mathrm{Id}$.

${ }^{236}$ GHANDNOOSH, supra note 220, at 16. 
implicit bias has not inflated the numbers of "innocent" Whites, can be entrusted with a gun to police bodies of color, more than the number of people in college. With respect to implicit bias screenings, measurements of bias are no more arbitrary than LSATs or standardized testing. The possibilities of using implicit bias research should be explored.

\section{CONCLUSION}

In order to hide, obfuscate, and legitimize its operations, white heteropatriarchy enlists the institutional power of the police and the courts. In the case of unarmed shootings, police departments provide a platform to perform white heteropatriarchy. The grand jury process legitimizes the performance. The weight of white heteropatriarchy inverts order, reallocates the burdens of proof and persuasion, and turns the investigation and grand jury proceeding on its head. When it places its finger on the scales of justice, it inverts judicial order, such that predators emerge as preyed, villains become victims, and the murdered are deserving of their own death. Because it is ubiquitous, omnipresent, and entrenched, white heteropatriarchy necessitates the use of multi-disciplinary set of critical analytical tools to unlock, unmask, and deconstruct its operations in order to cast its function in sharp relief for purposes of judgment and correction. In the case of implicit bias, scholars should explore the possibilities of using cognitive testing to screen applicants in law enforcement.

Given this current moment of hyper-racism, typified in the meteoric rise of Donald Trump as the Republican Party nominee for President, these rituals of violence will occur with greater frequency, and if uninterrupted, will occasion the collective loss of our humanity as well as a criminal justice system plagued with diminishing moral authority. Given the enormous consequences, disruption of white heteropatriarchy as an operative in law enforcement and the judicial realm is mandatory. 
